\title{
Wearable Devices for Environmental Monitoring in the Built Environment: A Systematic Review
}

\author{
Francesco Salamone $^{1,2, *(\mathbb{D})}$, Massimiliano Masullo ${ }^{2} \mathbb{D}$ and Sergio Sibilio $^{2}(\mathbb{D}$ \\ 1 Construction Technologies Institute, National Research Council of Italy (ITC-CNR), Via Lombardia, 49, \\ San Giuliano Milanese, 20098 Milano, Italy \\ 2 Department of Architecture and Industrial Design, Università degli Studi della Campania "Luigi Vanvitelli", \\ Via San Lorenzo, Abazia di San Lorenzo, 81031 Aversa, Italy; massimiliano.masullo@unicampania.it (M.M.); \\ sergio.sibilio@unicampania.it (S.S.) \\ * Correspondence: salamone@itc.cnr.it or francesco.salamone@unicampania.it; Tel.: +39-0-2980-6213
}

check for updates

Citation: Salamone, F.; Masullo, M.; Sibilio, S. Wearable Devices for Environmental Monitoring in the Built Environment: A Systematic Review. Sensors 2021, 21, 4727. https://doi.org/10.3390/s21144727

Academic Editor: Jose

A. Antonino-Daviu

Received: 10 June 2021

Accepted: 6 July 2021

Published: 10 July 2021

Publisher's Note: MDPI stays neutral with regard to jurisdictional claims in published maps and institutional affiliations.

Copyright: (c) 2021 by the authors. Licensee MDPI, Basel, Switzerland. This article is an open access article distributed under the terms and conditions of the Creative Commons Attribution (CC BY) license (https:/ / creativecommons.org/licenses/by/ $4.0 /)$.

\begin{abstract}
The so-called Internet of Things (IoT), which is rapidly increasing the number of networkconnected and interconnected objects, could have a far-reaching impact in identifying the link between human health, well-being, and environmental concerns. In line with the IoT concept, many commercial wearables have been introduced in recent years, which differ from the usual devices in that they use the term "smart" alongside the terms "watches", "glasses", and "jewellery". Commercially available wearables aim to enhance smartphone functionality by enabling payment for commercial items or monitoring physical activity. However, what is the trend of scientific production about the concept of wearables regarding environmental monitoring issues? What are the main areas of interest covered by scientific production? What are the main findings and limitations of the developed solution in this field? The methodology used to answer the above questions is based on a systematic review. The data were acquired following a reproducible methodology. The main result is that, among the thermal, visual, acoustic, and air quality environmental factors, the last one is the most considered when using wearables even though in combination with some others. Another relevant finding is that of the acquired studies; in only one, the authors shared their wearables as an open-source device, and it will probably be necessary to encourage researchers to consider open-source as a means to promote scalability and proliferation of new wearables customized to cover different domains.
\end{abstract}

Keywords: environmental monitoring; wearable devices; wearables; systematic review; visual environmental factor; acoustic environmental factor; thermal environmental factor; air quality environmental factor

\section{Introduction}

The so-called Internet of Things (IoT), a spider web of networked and interconnected objects that have proliferated over the past decade, could have a far-reaching impact on determining the relationship between human health and environmental quality [1] due to its ubiquitous intelligence [2].

Various studies have made it possible to thoroughly investigate the potential of IoT to improve all aspects of our lives, from industrial IoT to connected health or smart cities [3-5]. Among the IoT devices, the smartphone is the most widely used. In fact, the smartphone has become a disruptive presence in all essential various human activities: in some applications, the smartphone can be used to check the health of the users [6], or it can be used to acquire geographic coordinates from the real life of the users, which define the most relevant "place-of-interest", described as "a location where the user usually goes and stays for a while" [7]. Smartphones can also be used to record information for user-profiling, and they can also influence the level of life satisfaction [8,9]. 
While smartphones have been confirmed as a ubiquitous technology that inevitably interferes with our daily lives, more and more users are also interested in using wearable devices or simply wearables. Google Trends, a service that provides accurate and representative information about users' online search habits, reports on the global rise in consumer interest over the past decade for the keyword "wearable" (Figure 1).

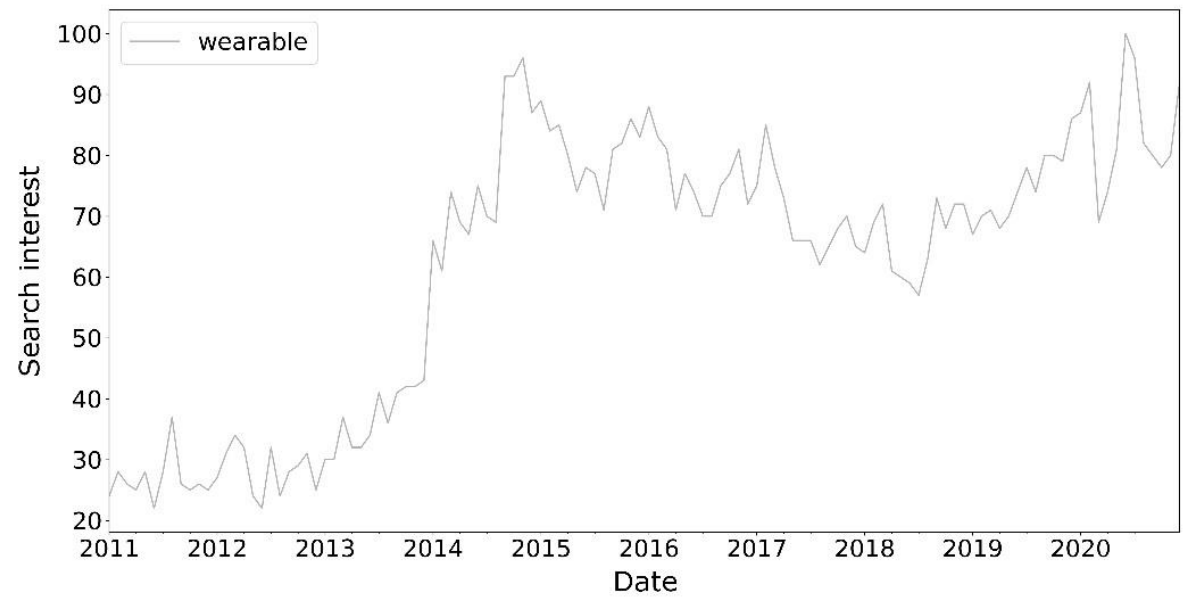

Figure 1. The global trend over the last 10 years of the keyword "wearable"-Google, 2020.

Figure 1 highlights the increasing interest of consumers in wearable devices, who are probably attracted by the desire to improve the quality of life or because their behaviour may also be influenced by IT vendors who, because the smartphone market is mature, try to create new advertising campaigns [10] to create a new demand for mobile devices, focusing their attention on smartbands and smartwatches [11] without considering real needs and investing in research to prove the effectiveness of their products [12].

While there are different practical experiences with the use of wearables for ergonomics [13] or health monitoring [14,15] and workers' safety [16], few researchers have investigated the impact of IoT-based infrastructure in environmental monitoring in the last decades. In [17], the authors systematise knowledge in the field of industrial wearables' safety to assess the relevance of their use in enterprises as the technology maintaining occupational safety, to correlate the benefits and costs of their implementation, and, to outline promising directions for future work in this area.

In $[18,19]$, the authors performed an extensive literature review of low-cost sensing technologies for air quality monitoring and exposure assessment and for monitoring air pollution and physical activity using sensors. In [20], the authors reviewed miniaturised sensors to measure airborne gasses and Particulate Matter (PM). In [21], the potential of different sensor-based modules for air quality monitoring was analysed in terms of power consumption, cost, response time, and lifetime. In [22], the authors presented a literature review of current research and developments on wearable devices from both academia and industry to be considered for environmental monitoring as a whole. In [23], the authors focused on low-cost IEQ sensors and cloud-based platforms to create holistic, personalized, and scalable well-being monitoring systems. They emphasised the need for wearables to create personalised approaches to IEQ monitoring.

Our study differs from the above works. It is the only one that conducts a systematic review on the four different environmental factors (visual, acoustic, thermal, and air quality) and uses the results to define the trends of research of wearables for environmental monitoring.

But, when was the term wearable introduced, and how can it be defined? What are the main considered areas of environmental monitoring? The following two sections will provide answers to these questions. 


\subsection{Introduction to Wearables}

Even though the first example of clothing with smart capabilities referred to the 1980s, with an example of a shoe-based computer, designed and developed to assist gamblers in a casino [24], the term "wearable" was first used in the scientific literature in 1996 when, in [25], the author presented a personal imaging system and, in [26], where the author gave an overview of energy generation during the user's daily activities, removing the technological limitation of batteries to power wearables. In 1997, the researchers of MIT media laboratory, Picard and Healey, used the term "affective wearables" [27] to refer to a system equipped with sensors that allowed detecting affective patterns, such as heart rate variability and electrodermal activity. To date, the class of wearable electronics or technologies, called "wearables" for short, has attracted increasing public interest and is generally identified as a category of devices that can be worn or tattooed on the human skin or even implanted in the human body to continuously and accurately monitor some variables (biometric in most of the cases, but also environmental in some other cases) without interrupting or restricting the user's movements [28].

The United International Children's Emergency Fund (UNICEF) also addressed the issue of wearables by proposing a competition on wearable design, with the intent of highlighting the ethical implications of wearable research. In this context, UNICEF aimed to highlight the potential of wearables to not only help consumers become more active, but also to improve their quality of life, thus promoting social interest among the public. UNICEF recommended the following requirements for potential wearables: low-cost, low power consumption, robustness and durability, scalability, and created to be open source and in the public domain $[29,30]$.

The many commercial wearables that have entered the market in recent years do not seem to meet the above prerequisites but rather serve commercial purposes by connecting watches, glasses, jewellery, which differ from standard devices only by the term "smart" [31], to the smartphone in order to improve its functionality, enabling, for example, payment for commercial objects, monitoring of physical activity [32], and collection of personal biometric data.

\subsection{Environmental Factors to Be Monitored}

Environmental Quality (EQ) can be subdivided by analysing it in terms of Indoor EQ (IEQ) or Outdoor EQ (OEQ). Both IEQ and OEQ are important to ensure the health and well-being of people.

It is well known that users spend a large part of their time indoors, so the quality of environments within buildings and the satisfaction and well-being of occupants is a hot topic today [33].

Especially in low-cost housing, where the limited indoor space may lead occupants to spend more time doing various outdoor activities, the quality of the outdoor environment is crucial [34].

Both IEQ and OEQ refer to a holistic concept that includes various environmental factors: visual, acoustic, thermal, and air quality.

Considering the thermal aspect in indoor environments, it is possible to improve occupant satisfaction and productivity [35]. The thermal aspect is also widely considered in outdoor spaces to understand the human response to the environment, especially in the hot season when the heat island effect, defined as the phenomenon in which the temperature recorded in an urban area tends to be higher than the surrounding areas, becomes more an issue to be considered by policymakers and for which mitigation measures have to be considered [36].

The air quality factor is another important aspect to be considered, which dramatically impacts the productivity and health of users indoors [37] and outdoors [38]. The concentrations of some variables or indoor pollutants $\left(\mathrm{CO}_{2}\right.$, VOCs, $\left.\mathrm{PM}, \mathrm{NO}_{2}\right)$ correlate strictly with those monitored outdoors, depending on the ventilation settings and indoor 
or outdoor production. As can be seen, air quality is a very important issue and is often analysed through wearables.

Visual environmental factor in indoor spaces has been shown to affect mental health and productivity of occupants [39]. It could have a cross-modal or combined effect on the perception of other Environmental Effects (EFs). This is probably the only EF studied more thoroughly in indoor environments due to controlling and optimising artificial lighting systems and daylighting.

The acoustic EF has been widely studied indoors and outdoors. Many of the principles and investigations could be applied indiscriminately indoors and outdoors [40-44].

In all cases, monitoring all four environmental factors could be helpful to understand the complex area of interaction (cross-modal or combined) among the different environmental aspects and user perception of IEQ or OEQ. In order to link the term wearables with the environmental aspect, some new acronyms have been introduced to emphasise the class of IoT devices for monitoring some environmental factors [45]: Personal Environmental Monitoring System (PEMS), an IoT device, to measure indoor environmental exposure to contaminant [45] and Wearable Environmental Monitoring System (WEMS), usually used outdoors, which can also communicate with PEMS [45].

This article aims to answer the following main question: What is the global trend in the scientific literature regarding environmental monitoring with wearables? To this aim, a customised query was used through a specific search engine.

The following sections describe the methodology to define the query and how the acquired data were used to perform the systematic review and the most relevant scientific literature findings related to wearables and environmental monitoring. Limitations are discussed in the conclusions section, with some future improvements.

\section{Methodology}

The methodology for collecting the papers consists mainly of two steps: the identification of the database to use and the definition of the query for downloading the metadata used for the systematic review.

The first was about establishing the database from which the information was obtained. In this case, the Scopus database was selected. Among the different available databases (e.g., PubMed, Web of Science, Google Scholar), the Scopus search engine, developed by Elsevier, was used. Its resources include Institute for Scientific Information (ISI) and Scopus-indexed papers. Scopus focused primarily on the field of physical sciences, health sciences, life sciences, and social sciences [46], which is consistent with the aim of this research. The covered period is from 1966 to the present [46]. Also, this aspect is consistent with our systematic review since, as reported in the previous Section 1.1, the oldest paper presenting a "wearable" device with computational capabilities was published in the 1980s. More details about the characteristics of the main databases can be found in [46]. Scopus provides an advanced search that allows more operators and codes to make a specific query. The search results in Scopus can be exported in different formats [46]. Scopus provides all metadata as furnished by publishers for all indexed content, including authors, affiliations, the title of the paper, abstract, authors and related affiliations, year of publication, volume, issue, pages, number of citations, type of document, Digital Object Identifier (DOI).

A comprehensive and detailed search guide can be found in [47]. All defined queries can be url-encoded, saved, and a notification can be enabled to get information about newly published works matching the defined query.

Once the search domain was defined, considering the advanced search functionality of Scopus, four different queries were defined related to the specific EFs among the ones considered: thermal, visual, acoustic, and air quality. In defining the four queries, a screening process was performed before downloading the data to avoid capturing papers not in line with the review's objective.

The general query structure was the same for the four EFs (Figure 2). 
1

TITLE-ABS-KEY ((wearable OR pems OR wems) AND (... OR ... OR ... ("proton exchange membrane" OR "fuel cell")) OR EID(...) AND NOT EID ((...)OR(...)) AND (EXCLUDE (DOCTYPE, "Cr")) 5 
The publication year range was not specified in the overall query structure: it was directly defined by the year of availability of the papers.

Regards the inclusion (and non-inclusion) of some articles via the EID code, as performed in Sections 6 and 7, it is possible to highlight that choosing the potential eligibility or ineligibility of a study, it could be possible to affect the review by a bias [51] due to the personal decision performed by a single author. To avoid this circumstance, a laborintensive, time-consuming, double data extraction was performed by two authors. As a result, they came to a consensus over discrepancies through discussion and in consultation with the third author, in line with the suggestion reported in [52]. In particular, the EID string provided by Scopus was used in Sections 6 and 7 to assure reproducibility and transparency of the selection criteria, in line with the requirements provided by [53].

Figure 3 reports the Preferred Reporting Items for Systematic reviews and MetaAnalyses (PRISMA) [54] flow diagrams for all four EFs, allowing to present the flow of information on how studies were found, collated, and screened for systematic reviews.

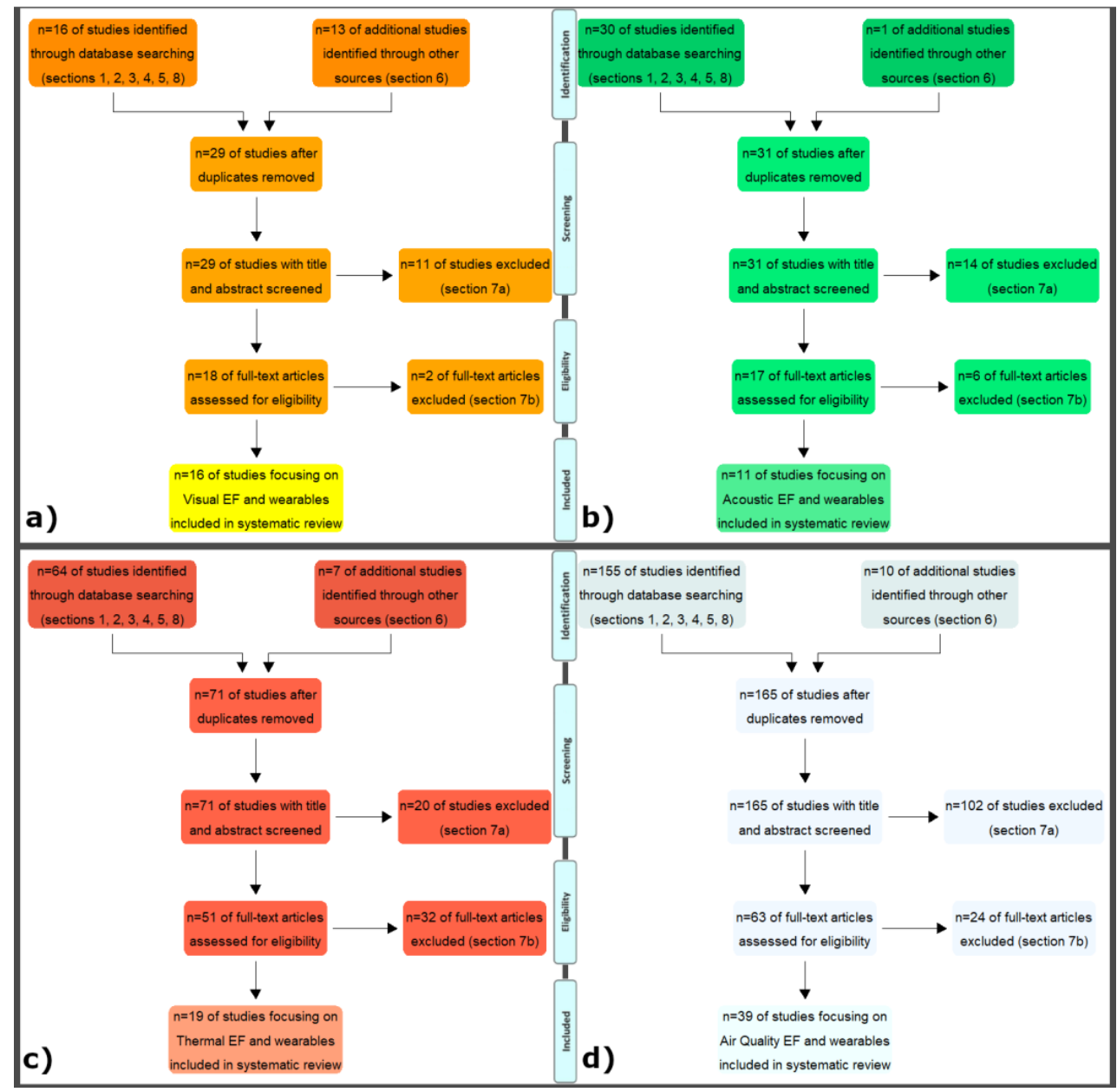

Figure 3. PRISMA flow diagrams: (a) Visual EF; (b) Acoustic EF; (c) Thermal EF; (d) Air Quality EF. The number of sections refers to query structure (Figure 2).

It is possible to highlight how in all four EFs, the additional studies were added only if they were not acquired by Scopus search. Consequently, the duplicates papers are null and the total number of papers considered in the following steps is exactly the sum of the papers from the database search plus the additional ones derived from Section 6.

The final queries for all four EFs are reported in Appendix A.

It can be observed that Section 6 reports only one additional EID for acoustic EF, while Section 7 is quite relevant for air quality EF: this is mainly since some of the research studies 
report emission measurement monitored by portable systems installed on board of off-road construction equipment, trucks.

For the four queries, the number of selected documents (search performed in April 2021) is of the same order of magnitude for acoustic (11) and visual (16), as well as thermal (19) and air quality (39).

To check the consistency of the considered terms, each of the four .csv was downloaded. Of the various available columns, only those related to the title and the abstract were considered and merged into a single column. The text in each cell of this column was pre-processed: each sentence present in each cell was tokenised, and all punctuations marks, stop words, and words less than three letters in length were removed. Then, an exploratory analysis was performed to check a visual representation of text data using a word cloud defined considering the word cloud package for Python, where the importance of each word is displayed in terms of frequency of occurrence with font size (Figure 4). For each EFs, the 50 most frequent words in the text of the title and abstract were visualised, ensuring that the screening process was performed correctly and that the selected papers were consistent with the aim of the research.

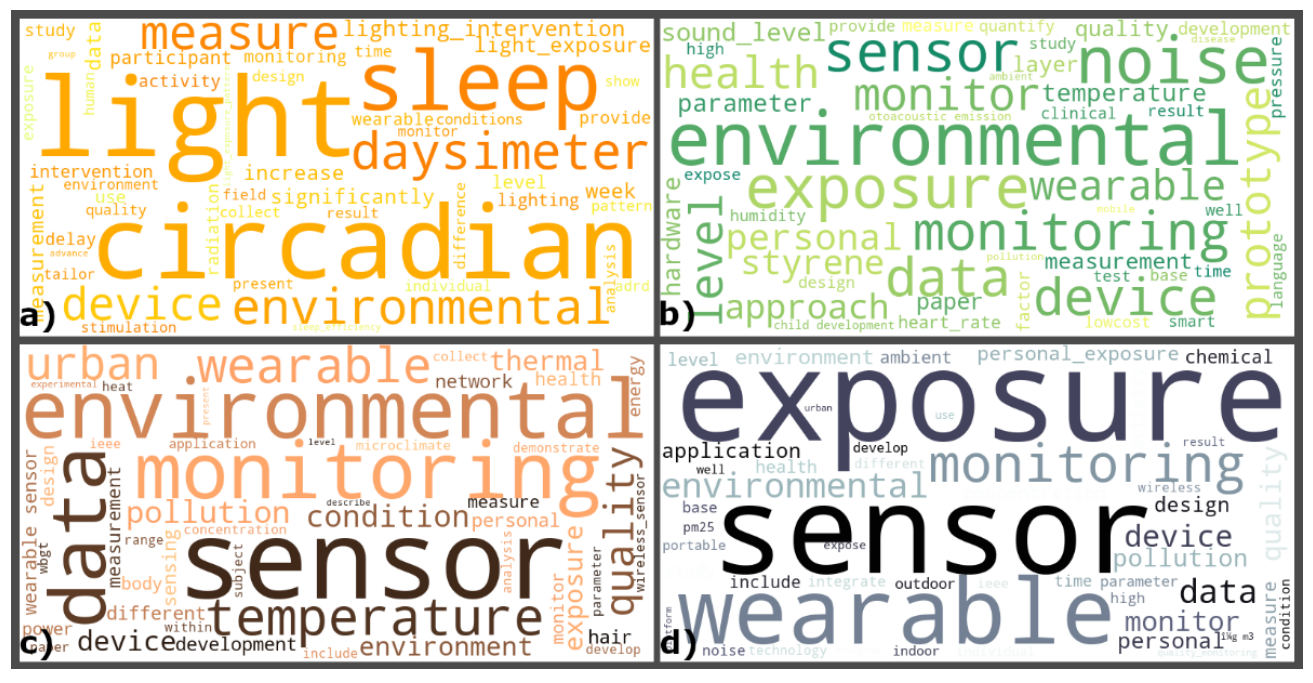

Figure 4. Exploratory Analysis with the word cloud of the most used terms in the title and abstract of the selected papers: (a) Visual EF; (b) Acoustic EF; (c) Thermal EF; (d) Air Quality EF.

In Figure $4 \mathrm{a}$, the frequent words are light, environmental, sleep, circadian, device, measure, daysimeter, the latter referring to a wearable device used to monitor the light to which the user is exposed.

In Figure $4 \mathrm{~b}$, among the most common words are noise, monitoring, exposure, health, wearable, environmental.

In Figure 4c, sensor, wearable, temperature, thermal, urban, and environmental are the most common words.

Finally, in Figure 4d, exposure, monitoring, wearable, sensors, and environmental are the most frequent words.

The document resulting from the search with the four queries were downloaded in ".csv" file format and considered for systematic review.

\section{Systematic Review}

The main findings resulting from the systematic review were defined separately for each of the four EFs.

\subsection{Monitoring of Visual EF with Wearables}

A total of 16 papers were considered for visual EFs, and 12 of them are based on the use of daysimeter, which was first introduced to the scientific community in 2005 [55]. In 
its first prototypical form, it was equipped with two sensors: a photopic sensor consisting of the Hamamatsu S1223-01 mounted in series with a subtractive glass filter and an opal glass; the other sensor was the Hammamatsu G1962 GaP, mounted in series with a colored glass filter (Schott Glass GG19) to achieve the proper short-wavelength radiation and a gel filter (Roscolux \#08, Pale Gold) that provides peak sensitivity to light with a wavelength of $440 \mathrm{~nm}$ and is called "blue" sensor for this reason [55]. During the development of this prototype, other alternative sensors were also considered. In all other developments, the device provides the measurement of optical radiation through a glass-filtered silicon photodiode that matches the standard photopic curve and a system consisting of a short-wavelength (blue) sensor equipped with a UV-blocking glass filter that has a long-wavelength cut-off at about $580 \mathrm{~nm}$ and a spectral response that peaks at $460 \mathrm{~nm}$. The data obtained from the device are downloaded and post-processed using the human circadian system response to light $\left(\mathrm{CL}_{\mathrm{A}}\right)$ model proposed in [56], which is used to define the Circadian Stimulus (CS) [57]. The board to which the photopic sensors are connected is also equipped with two orthogonally aligned accelerometers used to calculate an activity index defined as the root-mean-square deviation of acceleration in two dimensions, monitored every 30 s [57]. In a more advanced version, called Daysimeter-D, the two orthogonally oriented accelerometers have been replaced by three orthogonally oriented solid-state accelerometers to monitor the rest/activity pattern. The Daysimeter-D also allows the measurement of R, G, B, and IR channels with a peak spectral response at $615,530,460$, and $855 \mathrm{~nm}$, respectively [58]. The device was compared with other similar devices and calibrated in terms of illuminance [lx] and CLA, as reported in [59]. All described alternatives were used for indoor visual applications: laboratory, office, domestic environment, and hospital. As a practical implication, all these studies raise the need to consider a wearable system for measuring optical radiation in many applications related to human well-being, which may provide important insights into the relationship between circadian disruption [57] and well-being [60-67].

In other studies where the daysimiter is not considered, the scope of the research are different: in [68], a miniaturised microclimate station, specifically tailored to be worn while walking or cycling and therefore collecting data according to the pedestrian perspective in anthropogenic areas, was used to collect data on illuminance levels and some other variables related to thermal and air quality EFs; in [69], a calibrated wearable device, called Eco-Mini, used for environmental monitoring is presented; in [70], the authors showed how a textile composed of Janus chromic fibers shows stable practical performance and excellent sensitivity to UV/IR radiation to achieve real-time, energy-free, visual monitoring of IR radiation temperature and UV index; finally, in [71], the authors presented a fully low-cost and open-source (in accordance with the requirements defined by UNICEF, see Section 1.1) wearable light data logger for studying physiological and psychological effects of light.

Appendix B, Table A1, lists the papers that were selected and considered for this particular EF.

\subsection{Monitoring of Acoustic EF with Wearables}

A total of 11 papers were considered for acoustic EF.

In [72], the authors presented a wrist-worn device consisting of four layers: the two outermost layers are used to monitor the sound level and gasses in the environment. The two sensor layers are connected to the host layer by a layer called "flex interface" by the authors, which allows the connection of new hardware without developing a new physical layer. The main objective of this device development is to measure personal exposure to several physical (air humidity and temperature and air pressure) and chemical environmental parameters $\left(\mathrm{CO}\right.$ and $\left.\mathrm{NO}_{2}\right)$ known to be hazardous, in addition to the sound pressure level monitored by an analogue sound sensor MLMS-EMGN-4.0. In [73,74], the same authors focused on the design and development of the case of this wearable, which was manufactured using additive manufacturing techniques. In [75], the same authors 
reported the development of this multi-layered wearable that can capture parameters from the environmental, behavioural, and physiological domains.

In [76], the researchers presented the NEATVIBEwear device developed for the personal measurement of exposure to ultrafine particles (UFP) and noise in a pediatric population (it was tested at home and school), allowing the independent and/or combined effect of these environmental health exposures to be studied.

In [77], the authors justify using a smartphone with the NoiseSpy application and the Empatica E4 wearable with a striking correlation between noise and heart variability in outdoor environments. Particular is the case of [78], where workers employed in molding and in artifacts finishing were equipped with a commercial wearable device (Quest DLX1) to monitor noise exposure. Biological monitoring of styrene exposure using urine concentration was also conducted. The study revealed that the group of workers exposed to high noise level was also exposed to low styrene concentration. The group exposed to high styrene concentration near the limit of $20 \mathrm{ppm}$ was also exposed to the lowest noise level. This resulted in a significant negative correlation between otoacoustic emission and styrene concentration. In [69], the calibrated portable device Eco-Mini, already mentioned in the section of Visual EF, also allowed the measurement of Sound Pressure Levels. In [79], the authors demonstrated the feasibility of collecting personal Particulate Matter (PM2.5), language, noise data, cognitive assessments, and biospecimens from a sample of 3-4-yearold children using wearable ultrafine particle sensors and LENA—Language Environment Analysis System. Two different approaches were then collected to provide an example of real-time information on urban acoustic pollution [80] and overall personal pollution [81], where the PONG device can monitor ambient sound levels as well as VOCs and $\mathrm{NO}_{2}$, UVA and UVB, air temperature, relative humidity and air pressure data.

Appendix B, Table A2, lists the papers that were selected and considered for this particular EF.

\subsection{Monitoring of Thermal EF with Wearables}

A total of 19 papers were considered for thermal EF.

The studies reported in $[68,81]$ have already been presented and refer to the possibility of collecting thermal data from the pedestrian perspective in the city. In [82], the wearable enables the acquisition of representative data of urban microclimate conditions at a pedestrian level during a heatwave in a historical hilly city in central Italy. These data can be used to investigate microclimate variations within the city due to urban configuration and architectural design, human activities, and anthropogenic actions responsible for local overheating and to calculate direct thermal indices for human comfort assessment. In [83], the authors reported a research study on multi-stimuli (air temperature and UV) responsive chromism capable of displaying different colours in four different temperature ranges (blue at $\mathrm{T}<15^{\circ} \mathrm{C}$, green at $15^{\circ} \mathrm{C}<\mathrm{T}<33^{\circ} \mathrm{C}$, red at $33^{\circ} \mathrm{C}<\mathrm{T}<65^{\circ} \mathrm{C}$, and white $\mathrm{T}$ $>65^{\circ} \mathrm{C}$ ) covering a wide range of applications, more than just monitoring environmental conditions. In [84], the authors used different wearables to evaluate the effects of hair exposomes in Brazil. In [85], the authors estimated Heat Exposure of public service workers in Birmingham, Alabama, using thermometers attached to the workers' shoes. In [86], the authors present We-Safe, a self-powered sensor network system used for safety applications. In [87], the authors investigate an artificial, low-cost, skin-like temperature sensor that was highly flexible and provided for visual evaluation of temperature based on pectin and xanthan gum, which can be used in many fields such as electronic skin, human body temperature measurement, and environmental monitoring. Thus, this sensor can be used to alert people in real-time to prevent health issues resulting from extreme changes in human body temperature. In [88], the authors demonstrated the feasibility of a wearable wireless sensor system that can be attached to a uniform and used for temperature monitoring and can be activated remotely by an RF control signal. In [89], the authors presented a novel $\mathrm{MoS}_{2} / \mathrm{Cu}_{2} \mathrm{~S}$ hybrid grown on disposable cellulose paper using a hydrothermal method to measure relative humidity and temperature, among other physical quantities. The data 
can be wirelessly transmitted to a smartphone with an appropriate application. In [90], the authors presented a wearable sensor for analysing personal exposure to the thermal environment and air quality (ozone, particulate matter, $\mathrm{CO}$ ). The potential of the proposed solution is to fill the gap left by traditional air pollution monitoring. However, it still has a limitation due to the power consumption of the sensor. In [91], the authors present a smart indoor environment monitoring system for safety applications. It is based on custom wearable sensor nodes connected to a static WSN. The system is designed for a hazardous gas environment and thermal monitoring. However, it could also be used for several other safety applications or other areas, such as tracking medical devices in a hospital. In [92], a wearable system for continuous environment and health monitoring in chronic respiratory disease is presented, consisting of a wristband, a chest patch, and a handheld spirometer. In [93], the authors developed "MyPart" to address the need for a wearable device that combines accuracy, low cost, and portability in a single design. The study also reports the results of a preliminary user study conducted to evaluate the overall system's experience with appropriate results in terms of overall performance. In [94], various subjects wore a series of instruments that recorded individual microclimatic and physiological responses along a fixed pedestrian route that passed through various urban structures. Subjects experienced different thermal environments that could not be represented by fixed-point routine observation data. A clear dependence of sweating on gender and body size was found; men sweated more than women; overweight subjects sweated more than standard/underweight subjects. The temperature of the skin (Tskin) had a linear relationship with Standard Effective Temperature and a similar clear dependence on sex and body size differences: Tskin of the higher sweating groups was lower than that of the lower sweating groups, reflecting differences in evaporative cooling by sweating. In [95], the authors report on the design and initial deployment of the Citisense mobile air quality sensing system, which collects information about the thermal environmental and ambient air quality. In [96], the authors present in-depth knowledge on sensor selection and calibration of sensors for wearable applications for thermal and air quality assessment. In [97], laboratory testing of the prototype UPAS (Ultrasonic Personal Aerosol Sampler) shows excellent agreement with equivalent samplers in the federal reference method for gravimetric analysis of $\mathrm{PM}_{2.5}$ over a wide range of concentrations. UPAS also monitors thermal variables (air temperature and relative humidity). In [98], thermal data of the environment and skin temperature are collected by wearable sensors and a cloud platform for monitoring environmental parameters in e-health applications. The authors suggested that this type of monitoring system is not suitable for critical situations. However, many people suffering from chronic diseases and their families can benefit from this type of system.

Appendix B, Table A3, lists the papers that were selected and considered for this particular EF.

\subsection{Monitoring of Air Quality EF with Wearables}

A total of 39 papers were selected for air quality EF.

Depending on the substance to be monitored, all these studies can be divided into four main categories. The first group consists of research studies focusing on monitoring Volatile Organic Compounds (VOCs). VOCs include an extensive family of chemical substances: from aromatic to ketones, through alcohols, aliphatic, hydrocarbons, aldehydes, ethers, and acids. They can be emitted by building materials and during cooking, and increase their concentration indoors if they are poorly ventilated [99]. On the other hand, in outdoor spaces, the primary sources of VOCs are roads traffic, fossil fuel combustion, and pesticides. Due to the vast differences among chemical substances, the effects on human health from exposure to VOCs can be diverse: from skin or eye irritation to headaches, nausea, and cancer [100]. The selected studies can be divided into those in which wearables were used only for outdoor monitoring in this category. In particular, in [101,102], the wearable "Microfabricated Preconcentrator Chip- $\mu \mathrm{PC}$ " was used to show the potential applications in occupational risk assessment for specific occupations, such as industries involving direct 
handling of petroleum products or in large-scale asthma population studies in pediatric and teenagers. In [68], the previously presented wearable can also measure pedestrian exposure to VOCs in cities. In [103], the authors presented WearAir, an original expressive T-shirt that detects the air quality of the wearer's environment based on the measured volatile organic compounds. WearAir may be useful in motivating others to explore ways to communicate environmental information to lay people more effectively. The second subcategory refers to the study in which wearables were used indistinctly in indoor or outdoor environments. In [104], the authors demonstrated with a practical application the potential of the proposed wearable device to cope with many real-world analyte monitoring applications.

In $[105,106]$, the authors presented a cost-effective and reliable platform for personal exposure assessment. Several comparisons and tests showed that the proposed VOC device is suitable to characterise personal exposure in many real-world scenarios.

In [107], the authors presented a wrist-worn Asthma Research Tool (ART) designed to identify and detect asthma triggers using only low-cost components.

In [69], a wearable called "Eco-Mini" was presented, which the authors concluded overcomes the limitations of the first generation of low-cost environmental monitors that were generally not suitable for clinical environmental health studies due to practical challenges such as calibration, reproducibility, form factor, and battery life. In [108], the proposed wearable was able to detect not only VOCs but also $\mathrm{O}_{3}, \mathrm{NO}_{\mathrm{x}}$, and $\mathrm{CO}_{\mathrm{x}}$.

The second group of research studies consists of those that focus on monitoring Particulate Matter (PM), also called particle pollution. PMs come in many sizes and shapes and can consist of hundreds of different chemicals. Some are emitted directly from sources, such as construction sites, dirt roads, fields, smokestacks, or fires. In contrast, others result from the atmospheric reaction of $\mathrm{SO}_{2}$ and $\mathrm{NO}_{2}$, which in turn are produced by power plants, industries, and motor vehicles [109]. This research study category can be divided into those where the corresponding wearables are mainly used indoors, and those where they are indiscriminately applied indoors or outdoors, and those that are mainly outdoors. Research studies related to the first case include [110], where a wearable called "Ultrasonic Personal Aerosol Sampler-UPAS" was used to monitor $\mathrm{PM}_{2.5}$ in households in Honduras where rural women use wood-fired cookstoves. In [111], the authors conducted a research study to assess the exposure of worshippers to $\mathrm{PM}_{10}$ and $\mathrm{PM}_{2.5}$ in two different types of Buddhist temples in Tai-Chung. Samples were collected using Personal Environment Monitors (PEMs) connected to personal pumps flow rates of $2 \mathrm{~L} / \mathrm{min}$. The PEMs were worn by research staff, who mimicked the activities of the worshippers to determine their exposures to $\mathrm{PM}_{10}$ and $\mathrm{PM}_{2.5}$ in both temples. To reduce exposure to $\mathrm{PM}_{10}$ and $\mathrm{PM}_{2.5}$, the authors recommend spending less time in Buddhist temples, choosing a well-ventilated temple, or avoiding visiting temples on the first and 15th days of the lunar month. In the previously presented study [76], the authors used wearables to monitor noise and assess personal exposure of UFP (ultrafine particles) in the pediatric population, allowing researchers to examine the independent and/or combined effects of these health-related environmental exposures. The same research objective is pursued in the previously presented work [79], in which, in addition to the thermal and acoustic aspect, wearables worn by 3-4-year-old children are used to collect $\mathrm{PM}_{2.5}$ and $\mathrm{PM}_{10}$ data at school and home, demonstrating that it is possible to collect personal Particulate Matter with wearables when considering this population. In the previously presented work [90], the EnviroSensor 2.0 wearable was used in addition to thermal and location data in a laboratory test to evaluate the potential of this device to collect particulate matter, ozone, and $\mathrm{CO}$ concentration data.

Considering the studies on indoors and outdoors PM monitoring, the authors in [112] demonstrated the feasibility of using wearables for real-time remote air quality and health monitoring applications. In [113], an experiment was conducted in Athens-Greece to collect $\mathrm{PM}_{1}, \mathrm{PM}_{2.5}$, and $\mathrm{PM}_{10}$ data. It was shown that residential air quality was determined by the type and intensity of outdoor air sources and their vertical distance from the street. Indoor activities such as cooking and cleaning further increased PM concentrations 
and formulated air quality, while particle accumulation was evident. In [114], personal pollution monitoring and GPS tracking were used to assess children's PM $_{2.5}$ exposure in their everyday environment. The overall results of this study indicate that mean $\mathrm{PM}_{2.5}$ exposure was lowest for children who walked to and from school and higher for those who were driven. In $[115,116]$, the authors presented the results of a study conducted under the European Research Council funded "Cardiovascular Health effects of Air pollution in Telangana, India-CHAI" project, which investigated the association of particulate air pollution from outdoor and household sources with markers of atherosclerosis. In the previously presented study [93], the wearable "My part" was developed, distinguishing and counting particles of different sizes.

Finally, only two studies monitored PM only outdoors. In [117], a correlation was found between air quality indicators, participants' subjective feelings about air quality, physical activity status measured with wearable sensors, and reported health symptoms. Of particular note is the result of [118]. The authors used data collected by wearables to develop a machine learning model to identify periods of cycling activity necessary for estimating the inhaled dose of chemicals.

The third group of research studies consists of those that focus on monitoring of the $\mathrm{NO}_{2}$ and $\mathrm{CO}$. The first chemical is responsible for respiratory irritation or asthma in case of prolonged exposure [119]. While the second one, especially at elevated outdoor concentrations, may be of particular concern to people with some types of heart disease [120]. All the collected studies $[45,72,75,95,121-123]$ explain the development phase, the practical test and validation of a customized wearable device for environmental monitoring.

The fourth group refers to studies focused on monitoring of $\mathrm{CO}_{2}$ concentration with simple wearables [124] or wearables exchanging data with a Wireless Sensor Network (WSN) [91,125] or a LoRa network [126].

Finally, among the collected research papers, five cannot be classified into the abovereported groups. In [88], the authors demonstrated a wearable wireless sensor system that can be attached to a uniform and used to monitor the combustible gas concentration and air temperature that a RF control signal can remotely activate. In [127], a wireless wearable ring-based sensor system for rapid electrochemical monitoring of explosives and nerve agent in vapor and liquid phases was presented. In [92], the wearable collects ozone concentration data among the other thermal, biometric, and activity data. It is interesting to note the case of study [84] where two wearables, the MyExposome wristband and the 2BTech Personal Ozone Monitor, were used to collect data on environmental aggressors (Polycyclic aromatic hydrocarbons-PAHs, oxygenated PAHs-OPAHs, Polychlorinated biphenyls_PCBs, Pesticides, organophophorous flame retardants-OPFRs, Surface ozone content-SOC) associated with hair damage. In [78], a significant negative correlation was found between the otoacoustic emission levels and the concentration of the styrene urinary metabolites, in workers employed in molding and in artifacts refining.

Appendix B, Table A4, lists the papers that were selected and considered for this particular EF.

\section{Discussion and Conclusions}

Considering the Scopus functionality for combining search queries, a total of 68 papers can be summarised by entering the list number of each stored search query and the operator OR, some of which cover more than one EF. Figure 5 shows the annual scientific production for each $\mathrm{EF}$ and all $4 \mathrm{EFs}$. In this last case, the papers that consider wearables used for multiple EFs are counted only once. The period of publication is between 2000 and 2021. The first paper published in 2000 is related to the air quality research study conducted to assess the exposure of worshippers to $\mathrm{PM}_{10}$ and $\mathrm{PM}_{2.5}$ in two different types of Buddhist temples in Tai-Chung [111]. The second one, published in 2005, refers to visual EF when the daysimeter was first introduced to the scientific community [55]. 
Even though the systematic review covers the last 20 years, it can be highlighted from Figure 5 how only from 2012 onwards the most significant increase in production was recorded, with an annual growth rate of $12.18 \%$ considering all $4 \mathrm{EFs}$.

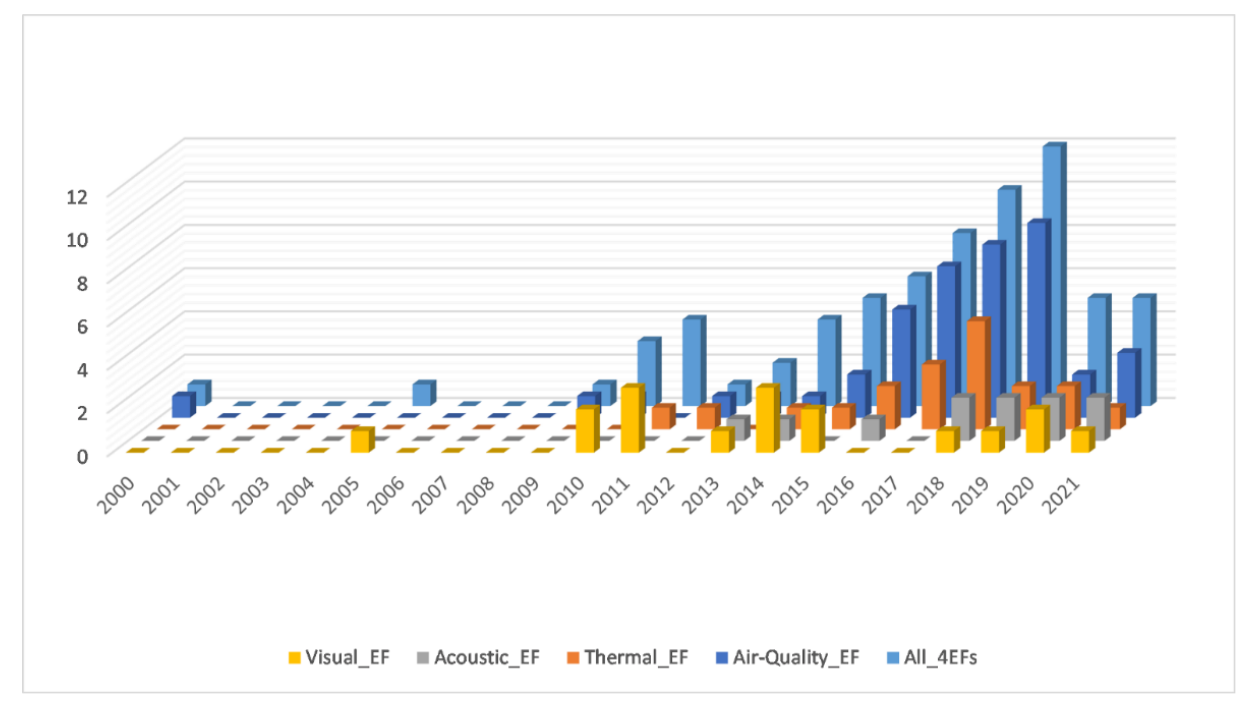

Figure 5. Annual Scientific production-Scopus, 2021.

Of the 68 papers, most consider wearables that can monitor various EFs. The wearables used to assess visual aspects focused mainly on indoor environments. Several studies looked at the impact of daylight on circadian rhythms.

As mentioned above, wearables used for visual EF were mainly focused on using daysimeters in different contexts or, alternatively, in defining the UV, IR, or illuminance values. Probably, in the future, studying the feasibility of using some type of wearable spectrometer for visual EF assessment could be considered, allowing the effects of visual aspects in the built environment to be examined from a human-centered perspective, more than has already been done.

Acoustic EF studies have mainly focused on investigating the health effects of combined acoustic and environmental air exposures. In a case study [77], a smartphone was used as a wearable monitoring device to understand the influence of noise on heart rate variability. The main problem in this perspective is accuracy across devices: different devices will have different microphones with different sensitivity levels, making measurements vary from device to device [128]. However, a more combined integration between physical wearables equipped with different sensors and a smartphone-based application also developed using an open-source framework [129], and integrated hardware could be interesting.

While for thermal EF, the use of wearables to assess outdoor comfort could be considered widespread, for example, tying the use of these wearables to specific outdoor conditions such as the Urban Heat Island and associated impacts on human well-being; instead, it is usually used in combination with some others to determine the overall environmental conditions while conducting the test.

Undoubtedly, among the four considered EFs, air quality is the most considered in the use of wearables, and the case studies span multiple domains, as seen in Section 3.4.

As the presented review shows, the data collected by wearables can be used to define the spatio-temporal propagation of environmental parameters. In some cases, these data are combined with subjective biometric data to identify a potential pattern. In a small number of cases, the environmental and biometric data are combined with subjective feedback. This aspect could probably be explored more deeply in the near future, in a human-centric approach. As mentioned in introduction, wearables have also been used to acquire data and assess physical ergonomic risk factors, particularly on unfavourable postures as reported in [13] where it was focused on the design principles of wearables 
from an ergonomic perspective as one of the main future directions that this type of device could address.

In healthcare monitoring [14], wearables have been used in research studies for monitoring chronic diseases such as asthma, cardiovascular diseases, diabetes and nutrition, gait and fall, neurological diseases, stress. In [15], it was pointed out that wearable devices used for health monitoring will face several limitations due to practical difficulties in achieving user-friendly solutions, security and privacy issues, and lack of industry standards.

In [16], it was emphasised that, although a considerable research effort has been devoted to the benefits of wearables in the work environment, less attention has been paid to the empirical analysis of employees' acceptance of wearable technology.

Ergonomic design principles, user-friendly solutions, and user acceptance of wearable technology are three main aspects that can be highlighted as the major directions that wearables used for environmental monitoring will also need to consider, more than it already has been done. From the table in Appendix B, there are no clear indications of the limitations of the proposed devices. However, after reading and viewing the photos reported in the papers, these wearables could be likely to be better integrated with clothing and apparel.

In $60 \%$ of the total cases, the accuracy of the tested system was performed simply by correlating monitored data with those acquired with calibrated sensors of a reference instrument. The percentages are quite different if each EF is considered separately: In $87 \%$ of the cases, a comparison or a calibration was performed for wearables used for monitoring visual aspects, while the accuracy of wearables used in the acoustic and thermal domain is verified in $45 \%$ of the cases. Even lower is the case of air quality monitoring using wearables, with only $40 \%$ of the tested devices. This is a limitation of the proposed wearables because a test of accuracy, if done consistently and in all cases, may reduce much of the variability and limitations of not-calibrated hardware. For all the four EFs, the devices are generally characterized by great usability when using the hardware while performing the monitoring campaign. The usability of software used for data extraction and analysis is not contemplated because it is performed in all the cases by specified researchers and not by direct involvement of participants who generally are not even aware of the measured value of the general environmental variable.

There is one point that did not emerge in this review paper that we would like to highlight as food for thought for likely future studies: related to one of UNICEF's requirements for this type of device (Section 1.1): of the 68 studies, how many fully shared their wearable to encourage dissemination by releasing it in open-source form? The answer is as disappointing as ever: only one. Work should be done in this direction, encouraging the proliferation of open-source wearables, to promote greater scalability and the proliferation of several devices applicable in different domains. In this sense, countries that are distinguished for their technologically advanced economy and society are reconsidering their education policy and are transferring funding to promote STEM education, an acronym that integrates the academic disciplines of Science, Technology, Engineering, and Mathematics [130], and probably, considering the investigated topic of wearables for environmental monitoring, especially when released under an open-source license, it could encourage both the development of more environmentally conscious society on the one hand and the spread of coding and programming in schools on the other [131].

Following the same principles of dissemination of information in an open and shared way, we decided to publish in an open-source journal, despite not having received funding for the research carried out. We have also shared the queries used in this systematic review (see Appendix A) to verify, in the future, how the studies in this specific area of research will evolve.

This is a future and distinct research direction for improving a widespread wearable device. We hope that this systematic review will highlight the current state of innovative work in wearable natural checking and provide rules to improve further the design and development of this type of device and related practical applications. 
Author Contributions: Conceptualization, F.S., M.M. and S.S.; methodology, F.S. and M.M.; data acquisition and analysis, F.S.; writing—original draft preparation, F.S.; writing—review and editing, F.S., M.M. and S.S. All authors have read and agreed to the published version of the manuscript.

Funding: This research received no external funding.

Institutional Review Board Statement: Not applicable.

Informed Consent Statement: Not applicable.

Data Availability Statement: Not applicable.

Conflicts of Interest: The authors declare no conflict of interest.

\section{Appendix A}

- Visual (16 resulting papers from 2005 to 2021): TITLE-ABS-KEY ((wearable OR pems OR wems) AND (daylight OR "color temperature" OR lighting OR luminance OR glare OR "dosimeter" OR "lux meter" OR "light meter" OR "color meter" OR colorimeter OR "luminance meter" OR photometry OR visual) AND (environmental W/3 monitoring) AND NOT ("proton exchange membrane" OR "fuel cell")) OR EID (2-s2.0273444552309 OR 2-s2.0-77956754851 OR 2-s2.0-85042561689 OR 2-s2.0-79957588325 OR 2-s2.0-84879967631 OR 2-s2.0-77953632392 OR 2-s2.0-81255124342 OR 2-s2.079952959932 OR 2-s2.0-84928173018 OR 2-s2.0-84960113897 OR 2-s2.0-84918811426 OR 2-s2.0-84907667703 OR 2-s2.0-85096669247) AND NOT EID ((2-s2.0-41849089305 OR 2-s2.0-85047120790 OR 2-s2.0-85052730774 OR 2-s2.0-84933505542 OR 2-s2.085044290759 OR 2-s2.0-84885042666 OR 2-s2.0-84952011313 OR 2-s2.0-85066239722 OR 2-s2.0-85087571429 OR 2-s2.0-85067399950 OR 2-s2.0-84855470006) OR (2-s2.085030837996 OR 2-s2.0-85086035889)) AND (EXCLUDE (DOCTYPE, “ $\left.\mathrm{cr}^{\prime \prime}\right)$ )

- Acoustic (11 resulting papers from 2013 to 2021): TITLE-ABS-KEY ((wearable OR pems OR wems) AND ("sound pressure" OR "noise" OR soundscape OR loudness OR "sound level meter" OR sound OR acoustic) AND (environmental W/3 monitoring) AND NOT ("proton exchange membrane" OR "fuel cell")) OR EID (2-s2.085101714199) AND NOT EID ((2-s2.0-84055184752 OR 2-s2.0-85074627122 OR 2-s2.085038856331 OR 2-s2.0-85102682462 OR 2-s2.0-37549066979 OR 2-s2.0-84885042666 OR 2-s2.0-84929223038 OR 2-s2.0-85045751469 OR 2-s2.0-84991109042 OR 2-s2.085069766055 OR 2-s2.0-85087571429 OR 2-s2.0-85068142712 OR 2-s2.0-85066081213 OR 2-s2.0-85097010457) OR (2-s2.0-85010934316 OR 2-s2.0-84984935795 OR 2-s2.084955466350 OR 2-s2.0-85015726258 OR 2-s2.0-85052392384 OR 2-s2.0-85086035889)) AND (EXCLUDE (DOCTYPE, "cr"))

- Thermal (19 resulting papers from 2011 to 2021): TITLE-ABS-KEY ((wearable OR pems OR wems) AND ("air temperature" OR "relative humidity" OR "radiant temperature" OR "air velocity" OR "wind velocity" OR "solar radiation" OR thermometer OR "temperature sensor" OR "humidity sensor" OR "Thermo Hygrometer" OR "Globe-Thermometer" OR "black globe temperature sensor" OR "anemometer" OR pyranometer OR thermal) AND (environmental W/3 monitoring) AND NOT ("proton exchange membrane" OR "fuel cell")) OR EID (2-s2.0-79960211999 OR 2-s2.084991057252 OR 2-s2.0-84990882596 OR 2-s2.0-84864975130 OR 2-s2.0-85012992224 OR 2-s2.0-85025664819 OR 2-s2.0-85041373985) AND NOT EID ((2-s2.0-85044576922 OR 2-s2.0-85102274461 OR 2-s2.0-85087280469 OR 2-s2.0-85042584638 OR 2-s2.079959682725 OR 2-s2.0-85101604122 OR 2-s2.0-84962616057 OR 2-s2.0-85067457161 OR 2-s2.0-85009960940 OR 2-s2.0-84891667975 OR 2-s2.0-85050642807 OR 2-s2.085021806905 OR 2-s2.0-85054856073 OR 2-s2.0-85100893557 OR 2-s2.0-0032856815 OR 2-s2.0-85099112380 OR 2-s2.0-84984696179 OR 2-s2.0-85089441482 OR 2-s2.085079714972 OR 2-s2.0-84959878599 OR 2-s2.0-85101108646 OR 2-s2.0-85103300483 OR 2-s2.0-85103941705 OR 2-s2.0-85096397030 OR 2-s2.0-85084811022 OR 2-s2.085086035889) OR (2-s2.0-85090275198 OR 2-s2.0-85079494843 OR 2-s2.0-85090949175 OR 2-s2.0-85058283726 OR 2-s2.0-85053684980 OR 2-s2.0-85053504654 OR 2-s2.0- 
85055675218 OR 2-s2.0-85034043945 OR 2-s2.0-85029159022 OR 2-s2.0-85027702156 OR 2-s2.0-85014596472 OR 2-s2.0-85037707375 OR 2-s2.0-84994102143 OR 2-s2.084974605210 OR 2-s2.0-85100591108 OR 2-s2.0-84934900174 OR 2-s2.0-84943615704 OR 2-s2.0-84896698814 OR 2-s2.0-70349666850 OR 2-s2.0-58149381900 OR 2-s2.041849089305 OR 2-s2.0-34347376912 OR 2-s2.0-85077977296 OR 2-s2.0-85076783804 OR 2-s2.0-85072645464 OR 2-s2.0-84991661572)) AND (EXCLUDE (DOCTYPE, “cr"))

- Air Quality (39 resulting papers from 2000 to 2021): TITLE-ABS-KEY ((wearable OR pems OR wems) AND ("CO2" OR "carbon dioxide" OR "VOCs" OR "volatile organic compounds" OR "NOx" OR "nitrogen oxides" OR "SOx" OR "sulphure oxides" OR "PM" OR "particulate matter" OR "concentration sensor" OR "air quality" OR pollution) AND (environmental W/3 monitoring) AND NOT ("proton exchange membrane" OR "fuel cell”)) OR EID (2-s2.0-84991057252 OR 2-s2.0-84990882596 OR 2-s2.084864975130 OR 2-s2.0-77950842815 OR 2-s2.0-85012992224 OR 2-s2.0-85019211807 OR 2-s2.0-85025664819 OR 2-s2.0-85032633215 OR 2-s2.0-85041373985 OR 2-s2.084978821913) AND NOT EID ((2-s2.0-84891667975 OR 2-s2.0-84991628256 OR 2-s2.079951809148 OR 2-s2.0-34548598391 OR 2-s2.0-85084482031 OR 2-s2.0-84865570477 OR 2-s2.0-84934900174 OR 2-s2.0-85103821669 OR 2-s2.0-79952613338 OR 2-s2.085059670087 OR 2-s2.0-85092552189 OR 2-s2.0-85045622832 OR 2-s2.0-84860692258 OR 2-s2.0-84930205795 OR 2-s2.0-72849107023 OR 2-s2.0-84942599257 OR 2-s2.00042123766 OR 2-s2.0-85083203437 OR 2-s2.0-85021741462 OR 2-s2.0-84880273197 OR 2-s2.0-84868228523 OR 2-s2.0-85017422700 OR 2-s2.0-85045234275 OR 2-s2.079960504035 OR 2-s2.0-84991661572 OR 2-s2.0-37549066979 OR 2-s2.0-0033626567 OR 2-s2.0-50849117829 OR 2-s2.0-85064530053 OR 2-s2.0-84958243072 OR 2-s2.085084696209 OR 2-s2.0-85097756884 OR 2-s2.0-85028048241 OR 2-s2.0-85053816691 OR 2-s2.0-85034962458 OR 2-s2.0-0035186649 OR 2-s2.0-85042029752 OR 2-s2.085060148578 OR 2-s2.0-85075976987 OR 2-s2.0-0032856815 OR 2-s2.0-85021647526 OR 2-s2.0-85100893557 OR 2-s2.0-85073126584 OR 2-s2.0-85092086462 OR 2-s2.080054756044 OR 2-s2.0-85085695131 OR 2-s2.0-84984935795 OR 2-s2.0-85044659217 OR 2-s2.0-85009268800 OR 2-s2.0-26244441016 OR 2-s2.0-84955466350 OR 2-s2.084978821913 OR 2-s2.0-85091572416 OR 2-s2.0-85066239722 OR 2-s2.0-85094163061 OR 2-s2.0-84890910781 OR 2-s2.0-0029825012 OR 2-s2.0-85015715897 OR 2-s2.034347229727 OR 2-s2.0-85098538986 OR 2-s2.0-85010934316 OR 2-s2.0-0034164368 OR 2-s2.0-85084811022 OR 2-s2.0-85084471284 OR 2-s2.0-84994174400 OR 2-s2.077956922071 OR 2-s2.0-0033179964 OR 2-s2.0-20444468078 OR 2-s2.0-70449564549 OR 2-s2.0-84900342694 OR 2-s2.0-24344499484 OR 2-s2.0-84953404270 OR 2-s2.084898682763 OR 2-s2.0-85077723989 OR 2-s2.0-85098056476 OR 2-s2.0-84870825370 OR 2-s2.0-0033207046 OR 2-s2.0-85090275198 OR 2-s2.0-85086135361 OR 2-s2.0-84885225815 OR 2-s2.0-85049913644 OR 2-s2.0-85064598441 OR 2-s2.0-85050642807 OR 2-s2.085054856073 OR 2-s2.0-85041278840 OR 2-s2.0-84991109042 OR 2-s2.0-84964470801 OR 2-s2.0-85061341557 OR 2-s2.0-79951790941 OR 2-s2.0-85101690645 OR 2-s2.00032261477 OR 2-s2.0-85015726258 OR 2-s2.0-85039737118 OR 2-s2.0-43049149412 OR 2-s2.0-84922212195 OR 2-s2.0-77954398091 OR 2-s2.0-84994102143 OR 2-s2.084864283881 OR 2-s2.0-84947241573 OR 2-s2.0-85089441482 OR 2-s2.0-85064164959 OR 2-s2.0-85053439823) OR (2-s2.0-85076971711 OR 2-s2.0-85075795237 OR 2-s2.085071043860 OR 2-s2.0-85086035889 OR 2-s2.0-85074049696 OR 2-s2.0-78650619960 OR 2-s2.0-0034849917 OR 2-s2.0-0036306120 OR 2-s2.0-0025717462 OR 2-s2.0-85077977296 OR 2-s2.0-85077051133 OR 2-s2.0-34250637151 OR 2-s2.0-85042542326 OR 2-s2.085013042267 OR 2-s2.0-84994468982 OR 2-s2.0-84883570280 OR 2-s2.0-85076783804 OR 2-s2.0-85089002492 OR 2-s2.0-85052392384 OR 2-s2.0-85096397030 OR 2-s2.085058283726 OR 2-s2.0-85046162925 OR 2-s2.0-85104610177 OR 2-s2.0-85052751178)) AND (EXCLUDE (DOCTYPE, “cr"))

\section{Appendix B}


Table A1. Selected papers for visual EF.

\begin{tabular}{|c|c|c|c|c|c|}
\hline $\begin{array}{l}\text { Reference Number of } \\
\text { the Research Study }\end{array}$ & $\begin{array}{c}\text { Visual Physical Variables } \\
\text { Monitored (in Brackets the Name } \\
\text { of the Used Wearable, if Available) }\end{array}$ & $\begin{array}{l}\text { Other Factors Monitored (in } \\
\text { Brackets the Name of Used } \\
\text { Wearable if Available) }\end{array}$ & $\begin{array}{l}\text { Indoor/Outdoor and Field } \\
\text { of Application }\end{array}$ & Practical Implication & $\begin{array}{l}\text { Limitation of the } \\
\text { Considered Wearable }\end{array}$ \\
\hline [68] & Lighting [lx] & Thermal, Air quality & $\begin{array}{l}\text { Outdoor. Wearable used to } \\
\text { study pedestrians' } \\
\text { exposure to urban } \\
\text { environmental conditions }\end{array}$ & $\begin{array}{l}\text { A miniaturized microclimate } \\
\text { station, specifically tailored to be } \\
\text { worn while walking or biking }\end{array}$ & \\
\hline$[60]$ & Circadian stimulus (Daysimeter) & & Indoor. Office sites & $\begin{array}{l}\text { CS } 0.3 \text { during daytime hours is } \\
\text { associated with an acute alerting } \\
\text { effect on office workers }\end{array}$ & \\
\hline [61] & $\begin{array}{l}\text { Personal light exposures: } \\
\text { illuminance, circadian light (CLA), } \\
\text { and circadian stimulus (CS) } \\
\text { levels (Daysimeter) }\end{array}$ & $\begin{array}{l}\text { Interdaily Stability (IS) and } \\
\text { Intradaily Variability (IV) }\end{array}$ & $\begin{array}{l}\text { Indoor. Household } \\
\text { environment }\end{array}$ & $\begin{array}{l}\text { The lighting intervention } \\
\text { significantly increased circadian } \\
\text { entrainment and significantly } \\
\text { reduced symptoms of depression } \\
\text { in the participants with ADRD } \\
\text { Flashing blue light delivered }\end{array}$ & \\
\hline [62] & $\begin{array}{c}\text { Personal light exposures: } \\
\text { illuminance, circadian light (CLA), } \\
\text { and circadian stimulus (CS) } \\
\text { levels (Daysimeter) }\end{array}$ & $\begin{array}{l}\text { Biometric monitoring } \\
\text { (Actigraph) }\end{array}$ & $\begin{array}{l}\text { Indoor. Household } \\
\text { environment }\end{array}$ & $\begin{array}{l}\text { Flashing blue light delivered } \\
\text { through closed eyelids during } \\
\text { sleep can change the circadian } \\
\text { phase, thus allowing to promote } \\
\text { sleep health in those suffering from } \\
\text { circadian sleep disorders. }\end{array}$ & \\
\hline [58] & $\begin{array}{c}\text { Personal light exposures: } \\
\text { illuminance, circadian light (CLA), } \\
\text { and circadian stimulus (CS) } \\
\text { levels (Daysimeter) }\end{array}$ & $\begin{array}{l}\text { Rest/activity monitoring } \\
\text { with three orthogonally } \\
\text { oriented, solid-state } \\
\text { accelerometers (Daysimeter) }\end{array}$ & $\begin{array}{l}\text { Indoor. Household } \\
\text { environment }\end{array}$ & $\begin{array}{l}\text { Circadian phase changes resulting } \\
\text { from a light intervention are } \\
\text { consistent with those predicted by } \\
\text { previously published Phase } \\
\text { Response Curves [132] }\end{array}$ & \\
\hline [63] & $\begin{array}{c}\text { Personal light exposures: } \\
\text { illuminance, circadian light (CLA), } \\
\text { and circadian stimulus (CS) } \\
\text { levels (Daysimeter) }\end{array}$ & & Indoor. & $\begin{array}{l}\text { A lighting intervention, tailored to } \\
\text { increase daytime circadian } \\
\text { stimulation, can be used to increase } \\
\text { sleep quality and improve } \\
\text { behavior in patients with ADRD }\end{array}$ & \\
\hline [59] & $\begin{array}{c}\text { Personal light exposures: } \\
\text { illuminance, circadian light (CLA), } \\
\text { and circadian stimulus (CS) } \\
\text { levels (Daysimeter) }\end{array}$ & & Indoor/Outdoor & & \\
\hline
\end{tabular}


Table A1. Cont.

\begin{tabular}{|c|c|c|c|c|c|}
\hline $\begin{array}{l}\text { Reference Number of } \\
\text { the Research Study }\end{array}$ & $\begin{array}{c}\text { Visual Physical Variables } \\
\text { Monitored (in Brackets the Name } \\
\text { of the Used Wearable, if Available) }\end{array}$ & $\begin{array}{l}\text { Other Factors Monitored (in } \\
\text { Brackets the Name of Used } \\
\text { Wearable if Available) }\end{array}$ & $\begin{array}{l}\text { Indoor/Outdoor and Field } \\
\text { of Application }\end{array}$ & Practical Implication & $\begin{array}{l}\text { Limitation of the } \\
\text { Considered Wearable }\end{array}$ \\
\hline$[64]$ & $\begin{array}{l}\text { Photopic illuminance in lux from } 400 \\
\text { to } 900 \mathrm{~nm} \text { (Philips Actiwatch-L) and } \\
\text { photopic illuminance in lux from } 400 \\
\text { to } 700 \mathrm{~nm} \text { (Daysimeter) }\end{array}$ & & Indoor. Hospital & $\begin{array}{l}\text { Study describes the difference } \\
\text { between light levels measured at } \\
\text { the wrist (Actiwatch-L) }\end{array}$ & \\
\hline [65] & $\begin{array}{l}\text { Personal circadian and photopic light } \\
\text { exposures (Daysimeter) }\end{array}$ & $\begin{array}{l}\text { Acceleration and temperature } \\
\text { data (Daysimeter) }\end{array}$ & Indoor. School & $\begin{array}{l}\text { Not significant difference between } \\
\text { two groups, one of which was } \\
\text { wearing orange glasses }\end{array}$ & \\
\hline$[66]$ & $\begin{array}{l}\text { Photopic illuminance in lux from } 400 \\
\text { to } 900 \mathrm{~nm} \text { (Philips Actiwatch-L) and } \\
\text { photopic illuminance in lux from } 400 \\
\text { to } 700 \mathrm{~nm} \text { (Daysimeter) }\end{array}$ & & $\begin{array}{l}\text { Indoor. Hospital } \\
\text { (day-shift nurse) }\end{array}$ & & \\
\hline [57] & $\begin{array}{l}\text { Photopic illuminance in lux from } 400 \\
\text { to } 900 \mathrm{~nm} \text { (Philips Actiwatch-L) and } \\
\text { photopic illuminance in lux from } 400 \\
\text { to } 700 \mathrm{~nm} \text { (Daysimeter) }\end{array}$ & & Indoor. Hospital & $\begin{array}{l}\text { These measurement and analysis } \\
\text { techniques may provide important } \\
\text { insights into the relationship } \\
\text { between circadian disruption } \\
\text { and well-being. }\end{array}$ & \\
\hline$[67]$ & $\begin{array}{c}\text { Personal light exposures } \\
\text { (illuminance, circadian light (CLA), } \\
\text { and circadian stimulus (CS) } \\
\text { levels) (Daysimeter) }\end{array}$ & $\begin{array}{l}\text { Biometric monitoring } \\
\text { (Actigraph) }\end{array}$ & Indoor. Home & $\begin{array}{l}\text { This case study provides beginning } \\
\text { support for the use of the } \\
\text { daysimeter in the home }\end{array}$ & \\
\hline [55] & $\begin{array}{c}\text { Personal light exposures } \\
\text { (illuminance, circadian light (CLA), } \\
\text { and circadian stimulus (CS) } \\
\text { levels) (Daysimeter) }\end{array}$ & & $\begin{array}{c}\text { Indoor. Laboratory } \\
\text { and Home }\end{array}$ & $\begin{array}{l}\text { A system of measurement of } \\
\text { optical radiation for the circadian } \\
\text { system is essential in many } \\
\text { applications concerning } \\
\text { human wellbeing }\end{array}$ & \\
\hline [69] & $\begin{array}{l}\text { Ambient light color } \\
\text { balance (Eco-Mini) }\end{array}$ & $\begin{array}{l}\text { Ozone, Sulfur Dioxide, } \\
\text { Volatile Organic Compounds, } \\
\text { humidity, temperature, and } \\
\text { sound level, 3-axis } \\
\text { accelerometer and GPS } \\
\text { location (Eco-Mini) }\end{array}$ & Indoor/Outdoor & $\begin{array}{l}\text { The presented wearable } \\
\text { environmental monitoring, called } \\
\text { "Eco-Mini", overcomes pratical } \\
\text { challenges (calibration, } \\
\text { reproducibility, form factor, and } \\
\text { battery life) and can be used in } \\
\text { clinical studies. }\end{array}$ & \\
\hline
\end{tabular}


Table A1. Cont.

\begin{tabular}{|c|c|c|c|c|c|}
\hline $\begin{array}{l}\text { Reference Number of } \\
\text { the Research Study }\end{array}$ & $\begin{array}{l}\text { Visual Physical Variables } \\
\text { Monitored (in Brackets the Name } \\
\text { of the Used Wearable, if Available) }\end{array}$ & $\begin{array}{l}\text { Other Factors Monitored (in } \\
\text { Brackets the Name of Used } \\
\text { Wearable if Available) }\end{array}$ & $\begin{array}{l}\text { Indoor/Outdoor and Field } \\
\text { of Application }\end{array}$ & Practical Implication & $\begin{array}{c}\text { Limitation of the } \\
\text { Considered Wearable }\end{array}$ \\
\hline [70] & UV light and IR radiation & & Indoor/Outdoor & $\begin{array}{l}\text { The fibers and their textiles showed } \\
\text { stable practical performance and } \\
\text { outstanding sensitivity to UV/IR } \\
\text { radiation to achieve energy-free, } \\
\text { real-time visual monitoring of the } \\
\text { IR radiation temperature, and } \\
\text { UV index. }\end{array}$ & \\
\hline$[71]$ & $\begin{array}{l}\text { UV Light, light intensity }[1 \mathrm{x}], \text { color } \\
\text { temperature }[\mathrm{K}] \text {, and color } \\
\text { components }\end{array}$ & & Indoor/Outdoor & $\begin{array}{l}\text { Practical value within disciplines } \\
\text { such as environmental and health } \\
\text { psychology, which seek to relate } \\
\text { psychological outcomes to } \\
\text { environmental exposure. } \\
\text { Completely open-source } \\
\text { allowing replicability. }\end{array}$ & \\
\hline
\end{tabular}

Table A2. Selected papers for acoustic EF.

\begin{tabular}{|c|c|c|c|c|c|}
\hline $\begin{array}{l}\text { Reference Number of } \\
\text { the Research Study }\end{array}$ & $\begin{array}{c}\text { Acoustic Physical Variables } \\
\text { Monitored (in Brackets the Name } \\
\text { of Used Wearable, if Available) }\end{array}$ & $\begin{array}{l}\text { Other Factors Monitored (in } \\
\text { Brackets the Name of Used } \\
\text { Wearable, if Available) }\end{array}$ & $\begin{array}{l}\text { Indoor/Outdoor and } \\
\text { Field of Application }\end{array}$ & Practical Implication & $\begin{array}{l}\text { Limitation of the } \\
\text { Considered Wearable }\end{array}$ \\
\hline [72] & $\begin{array}{l}\text { Sound pressure level [db] } \\
\text { (MLMS-EMGN-4.0) }\end{array}$ & $\begin{array}{l}\text { Thermal: air humidity, } \\
\text { temperature. Air quality: } \mathrm{CO} \\
\text { and } \mathrm{NO}_{2} \text {. Air pressure }\end{array}$ & Indoor. Laboratory & $\begin{array}{c}\text { This device measures several } \\
\text { physical and chemical } \\
\text { environmental parameters, } \\
\text { which are known to } \\
\text { be hazardous. }\end{array}$ & \\
\hline [76] & Noise exposure (NEATVIBEwear) & $\begin{array}{l}\text { Air quality: ultrafine particles } \\
\text { (UFP, }<100 \mathrm{~nm} \text { diameter) }\end{array}$ & $\begin{array}{l}\text { Indoor. Transit, } \\
\text { home, school }\end{array}$ & $\begin{array}{l}\text { Personal measurements of UFP } \\
\text { (ultrafine particle) and noise will } \\
\text { enable researchers to investigate } \\
\text { the independent and/or } \\
\text { joint-effects of these } \\
\text { health-relevant } \\
\text { environmental exposures. }\end{array}$ & $\begin{array}{l}\text { NEATVIBEwear, in its } \\
\text { current release, does not } \\
\text { allow for } 1 / 3 \text {-octave band or } \\
\text { spectral measurements of } \\
\text { traffic noise. }\end{array}$ \\
\hline
\end{tabular}


Table A2. Cont.

\begin{tabular}{|c|c|c|c|c|c|}
\hline $\begin{array}{l}\text { Reference Number of } \\
\text { the Research Study }\end{array}$ & $\begin{array}{c}\text { Acoustic Physical Variables } \\
\text { Monitored (in Brackets the Name } \\
\text { of Used Wearable, if Available) }\end{array}$ & $\begin{array}{l}\text { Other Factors Monitored (in } \\
\text { Brackets the Name of Used } \\
\text { Wearable, if Available) }\end{array}$ & $\begin{array}{l}\text { Indoor/Outdoor and } \\
\text { Field of Application }\end{array}$ & Practical Implication & $\begin{array}{l}\text { Limitation of the } \\
\text { Considered Wearable }\end{array}$ \\
\hline [73] & Sound pressure level [db] & $\begin{array}{l}\text { Thermal: air humidity, } \\
\text { temperature. Air quality: } \mathrm{CO} \\
\text { and } \mathrm{NO}_{2} \text {. Air pressure. } \\
\text { Motion activity (9 Degree of } \\
\text { Freedom(DoF)) motion } \\
\text { tracking by accelerometer } \\
(\mathrm{KX} 122-1037) \text {, gyroscope } \\
\text { (KXG03-1034) and } \\
\text { magnetometer } \\
\text { (KMX62-1031). }\end{array}$ & Indoor/Outdoor & $\begin{array}{l}\text { This device measures several } \\
\text { physical and chemical } \\
\text { environmental parameters, } \\
\text { which are known to be } \\
\text { hazardous. The wearable } \\
\text { solution may overcome the issue } \\
\text { of stationary climate sites, which } \\
\text { are rare in cities due to their size, } \\
\text { cost, and maintenance. }\end{array}$ & \\
\hline [74] & Sound pressure level [db] & $\begin{array}{l}\text { Thermal: air humidity, } \\
\text { temperature. Air quality: } \mathrm{CO} \\
\text { and } \mathrm{NO}_{2} \text {. Air pressure. } \\
\text { Motion activity ( } 9 \text { Degree of } \\
\text { Freedom(DoF)) motion } \\
\text { tracking by accelerometer } \mathrm{r} \\
\text { (KX122-1037), gyroscope } \\
\text { (KXG03-1034) and } \\
\text { magnetometer } \\
\text { (KMX62-1031). }\end{array}$ & Indoor/Outdoor & $\begin{array}{l}\text { This device is measuring several } \\
\text { physical and chemical } \\
\text { environmental parameters, } \\
\text { which are known to be } \\
\text { hazardous. The wearable } \\
\text { solution may overcome the issue } \\
\text { of stationary climate sites, which } \\
\text { are rare in cities due to their size, } \\
\text { cost, and maintenance. }\end{array}$ & \\
\hline [77] & $\begin{array}{l}\text { Smartphone with NoiseSpy } \\
\text { application }\end{array}$ & $\begin{array}{l}\text { Heart Rate Variability } \\
\text { (Empatica E4) }\end{array}$ & Outdoor & $\begin{array}{l}\text { The study shows the preliminary } \\
\text { results of user study with early } \\
\text { data analysis results, suggesting } \\
\text { a noticeable relationship between } \\
\text { noise and heart variability. }\end{array}$ & \\
\hline
\end{tabular}


Table A2. Cont.

\begin{tabular}{|c|c|c|c|c|c|}
\hline $\begin{array}{l}\text { Reference Number of } \\
\text { the Research Study }\end{array}$ & $\begin{array}{c}\text { Acoustic Physical Variables } \\
\text { Monitored (in Brackets the Name } \\
\text { of Used Wearable, if Available) }\end{array}$ & $\begin{array}{l}\text { Other Factors Monitored (in } \\
\text { Brackets the Name of Used } \\
\text { Wearable, if Available) }\end{array}$ & $\begin{array}{l}\text { Indoor/Outdoor and } \\
\text { Field of Application }\end{array}$ & Practical Implication & $\begin{array}{l}\text { Limitation of the } \\
\text { Considered Wearable }\end{array}$ \\
\hline [78] & Noise levels (Quest DLX-1) & $\begin{array}{l}\text { Biological monitoring in } \\
\text { saliva and in urine to } \\
\text { evaluate the exposure } \\
\text { to styrene }\end{array}$ & $\begin{array}{l}\text { Indoor. Workers } \\
\text { employed in molding and } \\
\text { in artifacts refining }\end{array}$ & $\begin{array}{l}\text { A significant negative correlation } \\
\text { was found between the } \\
\text { otoacoustic emission levels and } \\
\text { the concentration of the styrene } \\
\text { urinary metabolites. Otoacoustic } \\
\text { emissions, and particularly } \\
\text { distortion products, were able to } \\
\text { discriminate the exposed } \\
\text { workers from the controls, } \\
\text { providing also a rough estimate } \\
\text { of the slope of the dose-response } \\
\text { relation between otoacoustic } \\
\text { levels and styrene exposure }\end{array}$ & \\
\hline [69] & Sound pressure level (Eco-Mini) & $\begin{array}{l}\text { Ozone, Sulfur Dioxide, } \\
\text { Volatile Organic Compounds, } \\
\text { humidity, temperature, and } \\
\text { ambient light color balance, } \\
\text { 3-axis accelerometer and GPS } \\
\text { location (Eco-Mini) }\end{array}$ & Indoor/Outdoor & $\begin{array}{l}\text { The presented wearable } \\
\text { environmental monitoring, called } \\
\text { "Eco-Mini", overcomes practical } \\
\text { challenges (calibration, } \\
\text { reproducibility, form factor, and } \\
\text { battery life) and can be used in } \\
\text { clinical studies. }\end{array}$ & \\
\hline [79] & $\begin{array}{l}\text { Noise [db] (LENA-Language } \\
\text { Environment Analysis System) }\end{array}$ & $\begin{array}{c}\text { Thermal: air humidity, } \\
\text { temperature. Air quality: } \\
\text { PM }_{2.5} \text { an } \text { PM }_{10} \text {. } \\
\text { (PLANTOWER PM5003). }\end{array}$ & Indoor. School, Home. & $\begin{array}{l}\text { Preliminary results indicate that } \\
\text { it is feasible to gather personal } \\
\text { Particulate Matter (PM2.5), } \\
\text { language, and noise data, } \\
\text { cognitive assessments, and } \\
\text { biospecimens from a sample of } \\
\text { 3-4-year-old children. }\end{array}$ & \\
\hline
\end{tabular}


Table A2. Cont.

\begin{tabular}{|c|c|c|c|c|c|}
\hline $\begin{array}{l}\text { Reference Number of } \\
\text { the Research Study }\end{array}$ & $\begin{array}{l}\text { Acoustic Physical Variables } \\
\text { Monitored (in Brackets the Name } \\
\text { of Used Wearable, if Available) }\end{array}$ & $\begin{array}{l}\text { Other Factors Monitored (in } \\
\text { Brackets the Name of Used } \\
\text { Wearable, if Available) }\end{array}$ & $\begin{array}{l}\text { Indoor/Outdoor and } \\
\text { Field of Application }\end{array}$ & Practical Implication & $\begin{array}{l}\text { Limitation of the } \\
\text { Considered Wearable }\end{array}$ \\
\hline [75] & Sound level $[\mathrm{db}]$ & $\begin{array}{c}\text { Air quality: } \mathrm{NO}_{2}, \mathrm{CO} . \\
\text { Thermal: air temperature and } \\
\text { relative humidity. UV. } \\
\text { Biometrics: skin temperature, } \\
\text { heart rate. Motion activity (9 } \\
\text { Degree of Freedom(DoF)) } \\
\text { motion tracking by } \\
\text { accelerometer, gyroscope } \\
\text { and magnetometer. }\end{array}$ & Indoor/Outdoor & $\begin{array}{l}\text { Wrist-worn devices can integrate } \\
\text { parameters from the } \\
\text { environmental, behavioral, and } \\
\text { physiological domain }\end{array}$ & \\
\hline [80] & Noise level [db] & & Outdoor & $\begin{array}{l}\text { The main function of the } \\
\text { proposed study is to provide an } \\
\text { example of real-time information } \\
\text { on the acoustic impact on the city. }\end{array}$ & $\begin{array}{l}\text { This work is currently in } \\
\text { progress at this stage of the } \\
\text { project so that calibration and } \\
\text { adjustment of the final } \\
\text { acoustic sensor can be } \\
\text { carried out }\end{array}$ \\
\hline$[81]$ & Ambient sound level (PONG) & $\begin{array}{l}\text { Air quality: VOC and } \mathrm{NO}_{2} \text {. } \\
\text { Visual: UVA and UVB. } \\
\text { Thermal: air temperature, } \\
\text { relative humidity. Air } \\
\text { pressure. (PONG) }\end{array}$ & Outdoor & $\begin{array}{c}\text { The developed device has the } \\
\text { potential to serve as a personal } \\
\text { pollution monitor. }\end{array}$ & $\begin{array}{l}\text { Further work is required to } \\
\text { investigate the accuracy of } \\
\text { the data }\end{array}$ \\
\hline \multicolumn{6}{|c|}{ Table A3. Selected papers for thermal EF. } \\
\hline $\begin{array}{l}\text { Reference Number of } \\
\text { The Research Study }\end{array}$ & $\begin{array}{c}\text { Thermal Physical Variables } \\
\text { Monitored (in Brackets the Name } \\
\text { of Used Sensor or Wearable, } \\
\text { if Available) }\end{array}$ & $\begin{array}{l}\text { Other Factors Monitored (in } \\
\text { Brackets the Name of Used } \\
\text { Sensor or Wearable, if Available) }\end{array}$ & $\begin{array}{l}\text { Indoor/Outdoor and } \\
\text { Field of Application }\end{array}$ & Practical Implication & $\begin{array}{l}\text { Limitation of the } \\
\text { Considered Wearable }\end{array}$ \\
\hline [81] & $\begin{array}{l}\text { Air temperature }\left[{ }^{\circ} \mathrm{C}\right], \text { Relative } \\
\text { Humidity [\%]. (PONG). }\end{array}$ & $\begin{array}{c}\text { Air Quality: VOCS and } \mathrm{CO}_{2} \text {. } \\
\text { Visual: UV. Acoustic: ambient } \\
\text { sound levels. Air } \\
\text { pressure. (PONG). }\end{array}$ & Outdoor & $\begin{array}{c}\text { The developed device has the } \\
\text { potential to serve as a personal } \\
\text { pollution monitor. }\end{array}$ & \\
\hline
\end{tabular}


Table A3. Cont.

\section{Thermal Physical Variables
Reference Number of
Monitored (in Brackets the Nam \\ The Research Study \\ of Used Sensor or Wearable} if Available)
Other Factors Monitored (in

Brackets the Name of Used Sensor or Wearable, if Available)
Indoor/Outdoor and

Field of Application
Practical Implication

The data are representative of intra-urban microclimate conditions at a pedestrian height during a heat wave in a historical hilly town located in central Italy. These data can be used to investigate

microclimate variation within the city imputable to urban configuration and architectural layout, human activity, and anthropogenic actions responsible for local overheating, and to compute direct thermal indexes for human comfort evaluation.

This unit can demonstrate different colors in four different temperature ranges (blue at $\mathrm{T}<$ $15^{\circ} \mathrm{C}$, green at $15^{\circ} \mathrm{C}<\mathrm{T}<33$

${ }^{\circ} \mathrm{C}$, red at $33{ }^{\circ} \mathrm{C}<\mathrm{T}<65^{\circ} \mathrm{C}$ and white $\mathrm{T}>65^{\circ} \mathrm{C}$ Polycyclic aromatic

Visual: UV (UV dosimeter badge). Air quality: Polycyclic aromatic hydrocarbons-PAHs, oxygenated PAHs-OPAHs, Polychlorinated biphenyls-PCBs, Pesticides, organophophorous flame retardants-OPFRs.

(MyExposome); surface ozone content-SOC (2BTech Personal Ozone Monitor)

hydrocarbons (PAH) indicate possible causes of hair damages. This is the first meteorotropic study of its kind, combining environmental aggressors related to hair

damage, opening new research hypothesis and further studies on exposome.
Due to the limitation of the reaction chemistry, it's usually very difficult to change these color change styles for better stimuli sensing performance
Limitation of the Considered Wearable 
Table A3. Cont.

\begin{tabular}{|c|c|c|c|c|c|}
\hline $\begin{array}{l}\text { Reference Number of } \\
\text { The Research Study }\end{array}$ & $\begin{array}{c}\text { Thermal Physical Variables } \\
\text { Monitored (in Brackets the Name } \\
\text { of Used Sensor or Wearable, } \\
\text { if Available) }\end{array}$ & $\begin{array}{l}\text { Other Factors Monitored (in } \\
\text { Brackets the Name of Used } \\
\text { Sensor or Wearable, if Available) }\end{array}$ & $\begin{array}{l}\text { Indoor/Outdoor and } \\
\text { Field of Application }\end{array}$ & Practical Implication & $\begin{array}{l}\text { Limitation of the } \\
\text { Considered Wearable }\end{array}$ \\
\hline [86] & $\begin{array}{l}\text { Air Temperature and relative } \\
\text { humidity (BME680 mounted on a } \\
\text { WE-Safe wearable sensor node) }\end{array}$ & $\begin{array}{l}\text { UV (si1145 mounted on a WE-Safe } \\
\text { wearable sensor node) }\end{array}$ & Indoor/Outdoor. & $\begin{array}{l}\text { The proposed sensor network } \\
\text { system presents a good } \\
\text { example of an Internet of } \\
\text { Things (IoT) platform in health } \\
\text { care and safety applications. } \\
\text { This study investigates an } \\
\text { artificial low-cost skin-like } \\
\text { temperature sensor that was } \\
\text { highly flexible and allowed for } \\
\text { visual evaluation of the } \\
\text { temperature. It can be used to } \\
\text { provide real-time warnings to } \\
\text { people for preventing any } \\
\text { health issues resulting from } \\
\text { extreme changes in human } \\
\text { body temperature. }\end{array}$ & \\
\hline [68] & $\begin{array}{c}\text { Air Temperature }\left[{ }^{\circ} \mathrm{C}\right], \text { Relative } \\
\text { Humidity }[\%](\mathrm{BME} 280) . \text { Wind } \\
\text { Direction }\left[{ }^{\circ}\right], \text { Wind Speed }[\mathrm{m} / \mathrm{s}] \\
\text { (LCJ-CAPTEURS CV07-OEM). } \\
\text { Surface Temperature }\left[{ }^{\circ} \mathrm{C}\right] \text { (Flir vue } \\
\text { Pro R) }\end{array}$ & $\begin{array}{c}\text { Air quality: } \mathrm{CO} \text { (DDScientific GD) } \\
\text { and } \mathrm{CO}_{2} \text { (Dynament } \\
\text { MSH-P-CO } \mathrm{CO}_{2} / \mathrm{NC} \text { ) concentration } \\
\text { [ppm], VOCs [kOhm] (Figaro } \\
\text { TGS8100). Visual: Illuminance [lx], } \\
\text { Global solar radiance } \\
{\left[\mathrm{W} / \mathrm{m}^{2}\right] \text { (SP-215) }}\end{array}$ & $\begin{array}{l}\text { Outdoor. Wearable used } \\
\text { to study pedestrians' } \\
\text { exposure to urban envi- } \\
\text { ronmental conditions }\end{array}$ & $\begin{array}{l}\text { A miniaturized microclimate } \\
\text { station, specifically tailored to } \\
\text { be worn while walking or } \\
\text { biking and therefore to collect } \\
\text { data according to the } \\
\text { pedestrian perspective in } \\
\text { anthropized areas. }\end{array}$ & \\
\hline
\end{tabular}


Table A3. Cont.

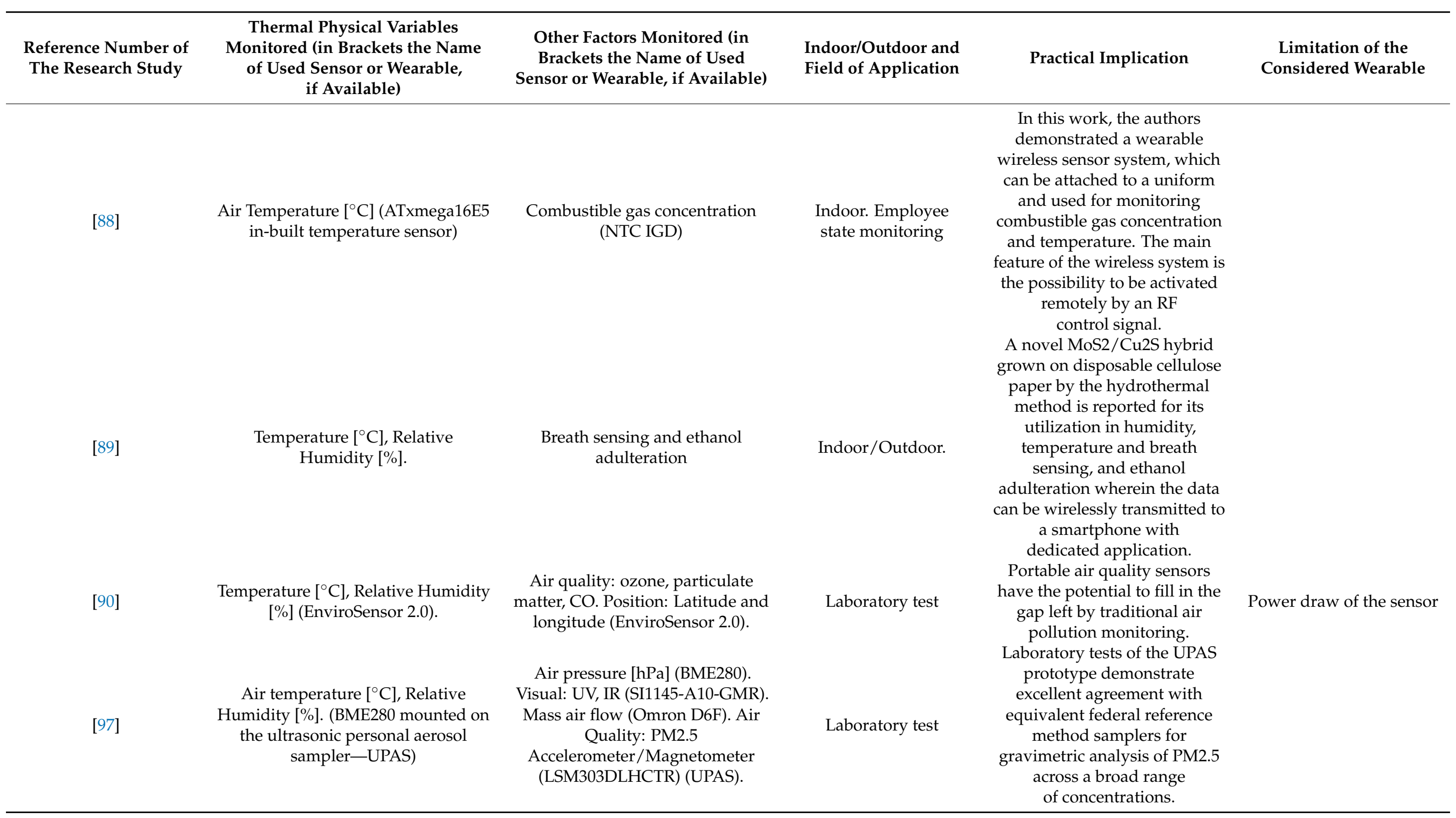


Table A3. Cont.

\begin{tabular}{|c|c|c|c|c|c|}
\hline $\begin{array}{l}\text { Reference Number of } \\
\text { The Research Study }\end{array}$ & $\begin{array}{c}\text { Thermal Physical Variables } \\
\text { Monitored (in Brackets the Name } \\
\text { of Used Sensor or Wearable, } \\
\text { if Available) }\end{array}$ & $\begin{array}{l}\text { Other Factors Monitored (in } \\
\text { Brackets the Name of Used } \\
\text { Sensor or Wearable, if Available) }\end{array}$ & $\begin{array}{l}\text { Indoor/Outdoor and } \\
\text { Field of Application }\end{array}$ & Practical Implication & $\begin{array}{l}\text { Limitation of the } \\
\text { Considered Wearable }\end{array}$ \\
\hline [91] & $\begin{array}{c}\text { Temperature }\left[{ }^{\circ} \mathrm{C}\right], \text { Relative Humidity } \\
{[\%](\mathrm{SHT} 11)}\end{array}$ & Air quality: $\mathrm{CO}_{2}[\mathrm{ppm}]$ & Indoor. & $\begin{array}{l}\text { The system based on custom } \\
\text { wearable sensor nodes, } \\
\text { connected to a static WSN has } \\
\text { been developed for a } \\
\text { hazardous gas environment, } \\
\text { but could be applied to a } \\
\text { number of other safety } \\
\text { applications or in other areas, } \\
\text { such as the tracking of medical } \\
\text { devices in a hospital. }\end{array}$ & \\
\hline [92] & $\begin{array}{c}\text { Temperature }\left[{ }^{\circ} \mathrm{C}\right], \text { Relative } \\
\text { Humidity }[\%] .\end{array}$ & $\begin{array}{l}\text { Air quality: Ozone. Biometric } \\
\text { parameters: Herat rate, respiratory } \\
\text { rate and expiratory airflow, skin } \\
\text { impedance. Acceleration. }\end{array}$ & Indoor. & $\begin{array}{l}\text { The system consists of a } \\
\text { wristband, a chest patch, and a } \\
\text { handheld spirometer. }\end{array}$ & \\
\hline [98] & $\begin{array}{c}\text { Temperature }\left[{ }^{\circ} \mathrm{C}\right] \text {, Relative Humidity } \\
{[\%] \text { (MyPart). }}\end{array}$ & $\begin{array}{l}\text { Air quality: distinguishing and } \\
\text { counting differently sized } \\
\text { particles (MyPart) }\end{array}$ & $\begin{array}{l}\text { Indoor. People suffering } \\
\text { from chronic diseases. }\end{array}$ & $\begin{array}{l}\text { The study reports the results of } \\
\text { a preliminary user study } \\
\text { conducted to evaluate the } \\
\text { experience of using a new } \\
\text { PEMS for air monitoring. } \\
\text { This type of monitoring } \\
\text { systems are not suitable for } \\
\text { critical situations, but many } \\
\text { people suffering from chronic } \\
\text { diseases and their families can } \\
\text { benefit from this type } \\
\text { of system. }\end{array}$ & \\
\hline
\end{tabular}


Table A3. Cont.

\section{Thermal Physical Variables \\ Reference Number of \\ The Research Study \\ Thermal Physical Variables \\ of Used Sensor or Wearable} if Available)
Other Factors Monitored (in

Brackets the Name of Used Sensor or Wearable, if Available)
Indoor/Outdoor and

Field of Application

\section{Practical Implication}

A clear dependence of

A clear dependence of
sweating on gender and bod size was found; males were found to sweat more than

females; overweight subjects sweat more than standard/underweight subjects. Tskin had a linear relationship with SET and depended on gender and body size differences. Tskin of the higher-sweating groups was lower than that of the lower-sweating groups, reflecting differences in evaporative cooling by perspiration.

Author reports the design and initial deployment of the Citisense mobile air quality sensing system.

This paper presents in-depth knowledge on sensor selection and calibration. 
Table A4. Selected papers for air quality EF.

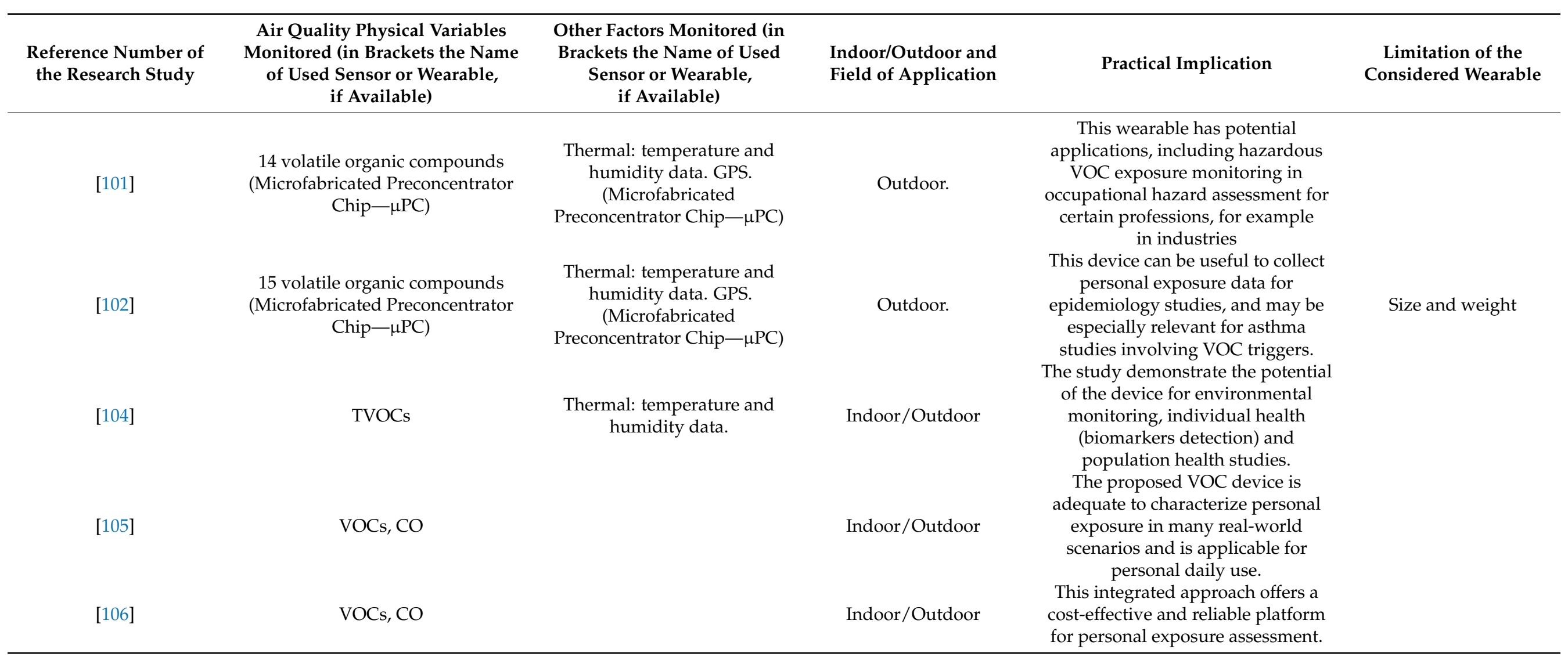


Table A4. Cont.

\begin{tabular}{|c|c|c|c|c|c|}
\hline $\begin{array}{l}\text { Reference Number of } \\
\text { the Research Study }\end{array}$ & $\begin{array}{c}\text { Air Quality Physical Variables } \\
\text { Monitored (in Brackets the Name } \\
\text { of Used Sensor or Wearable, } \\
\text { if Available) }\end{array}$ & $\begin{array}{l}\text { Other Factors Monitored (in } \\
\text { Brackets the Name of Used } \\
\text { Sensor or Wearable, } \\
\text { if Available) }\end{array}$ & $\begin{array}{l}\text { Indoor/Outdoor and } \\
\text { Field of Application }\end{array}$ & Practical Implication & $\begin{array}{l}\text { Limitation of the } \\
\text { Considered Wearable }\end{array}$ \\
\hline [107] & Ozone (MiCS-2614), TVOCs (SGPC3) & $\begin{array}{l}\text { Thermal: Air Temperature } \\
\text { and Relative humidity } \\
\text { (SHT30-DIS-B). } \\
\text { Accelerometer for activity } \\
\text { level (NXP MMA8652FC) }\end{array}$ & Indoor/Outdoor & $\begin{array}{l}\text { This work shows that an inexpensive } \\
\text { and compact wearable device can be } \\
\text { built, and it also reveals additional } \\
\text { improvement, particularly in } \\
\text { shortening of response time, } \\
\text { reducing cross interference from } \\
\text { unintended gases present in air, and } \\
\text { determining when recalibration is } \\
\text { necessary are all important for a } \\
\text { device intended for use under } \\
\text { real-world scenarios. }\end{array}$ & \multirow{4}{*}{$\begin{array}{l}\text { The system had not } \\
\text { been fully developed in } \\
\text { terms of the Internet } \\
\text { connectivity and } \\
\text { smartphone application. }\end{array}$} \\
\hline [45] & $\mathrm{CO}, \mathrm{NO}_{2}, \mathrm{O}_{3}$, and $\mathrm{SO}_{2}$ & $\begin{array}{l}\text { Thermal: Air Temperature } \\
\text { and Relative humidity. } \\
\text { Visual: UV. Accelerometer to } \\
\text { track a user's activity. }\end{array}$ & Indoor/Outdoor & $\begin{array}{l}\text { Outdoor and indoor air } \\
\text { quality assessment. }\end{array}$ & \\
\hline [110] & $\begin{array}{l}\text { Particulate matter-PM2.5 } \\
\text { (Ultrasonic Personal Aerosol } \\
\text { Sampler-UPAS) }\end{array}$ & & $\begin{array}{l}\text { Indoor. Rural Honduran } \\
\text { women who use } \\
\text { wood-burning } \\
\text { cookstoves. }\end{array}$ & $\begin{array}{l}\text { Using the UPAS as a personal } \\
\text { exposure monitor for household air } \\
\text { pollution studies. }\end{array}$ & \\
\hline [69] & $\begin{array}{l}\text { Ozone, Sulfur Dioxide, Volatile } \\
\text { Organic Compounds (Eco-Mini) }\end{array}$ & $\begin{array}{l}\text { Acoustic: Sound pressure } \\
\text { level. Thermal: relative } \\
\text { humidity, temperature. } \\
\text { Visual: ambient light color } \\
\text { balance, 3-axis accelerometer } \\
\text { and GPS location (Eco-Mini) }\end{array}$ & Indoor/Outdoor & $\begin{array}{l}\text { New forms of low-cost portable } \\
\text { monitors have begun to emerge that } \\
\text { enable the collection of higher spatial } \\
\text { density "crowd sourced" data. }\end{array}$ & \\
\hline
\end{tabular}


Table A4. Cont.

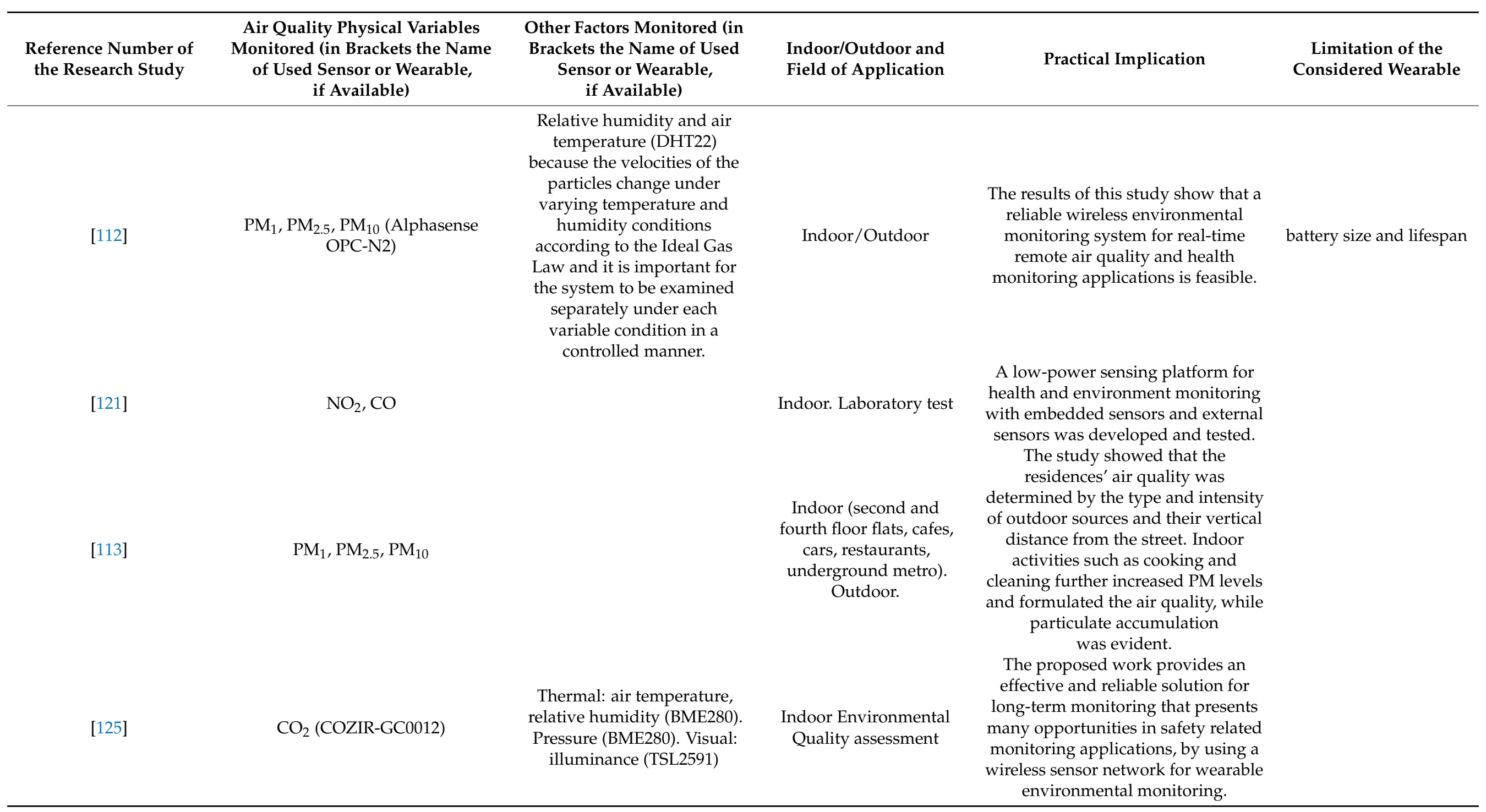


Table A4. Cont.

\begin{tabular}{|c|c|c|c|c|c|}
\hline $\begin{array}{l}\text { Reference Number of } \\
\text { the Research Study }\end{array}$ & $\begin{array}{c}\text { Air Quality Physical Variables } \\
\text { Monitored (in Brackets the Name } \\
\text { of Used Sensor or Wearable, } \\
\text { if Available) }\end{array}$ & $\begin{array}{l}\text { Other Factors Monitored (in } \\
\text { Brackets the Name of Used } \\
\text { Sensor or Wearable, } \\
\text { if Available) }\end{array}$ & $\begin{array}{l}\text { Indoor/Outdoor and } \\
\text { Field of Application }\end{array}$ & Practical Implication & $\begin{array}{l}\text { Limitation of the } \\
\text { Considered Wearable }\end{array}$ \\
\hline [122] & $\begin{array}{l}\qquad \mathrm{NO}_{2}, \mathrm{CO} \text { and } \mathrm{SO}_{2} \\
\text { additionally (Ubiqsens) }\end{array}$ & $\begin{array}{l}\text { Thermal: air temperature, } \\
\text { relative humidity. Pressure. } \\
\text { Acoustic: noise level. } \\
\text { Accelerometer, Gyroscope, } \\
\text { Magnetometer. (Ubiqsense) }\end{array}$ & Indoor. Laboratory test. & $\begin{array}{l}\text { The wearables for gas monitoring } \\
\text { under real laboratory conditions } \\
\text { show high potential. }\end{array}$ & \\
\hline
\end{tabular}


Table A4. Cont.

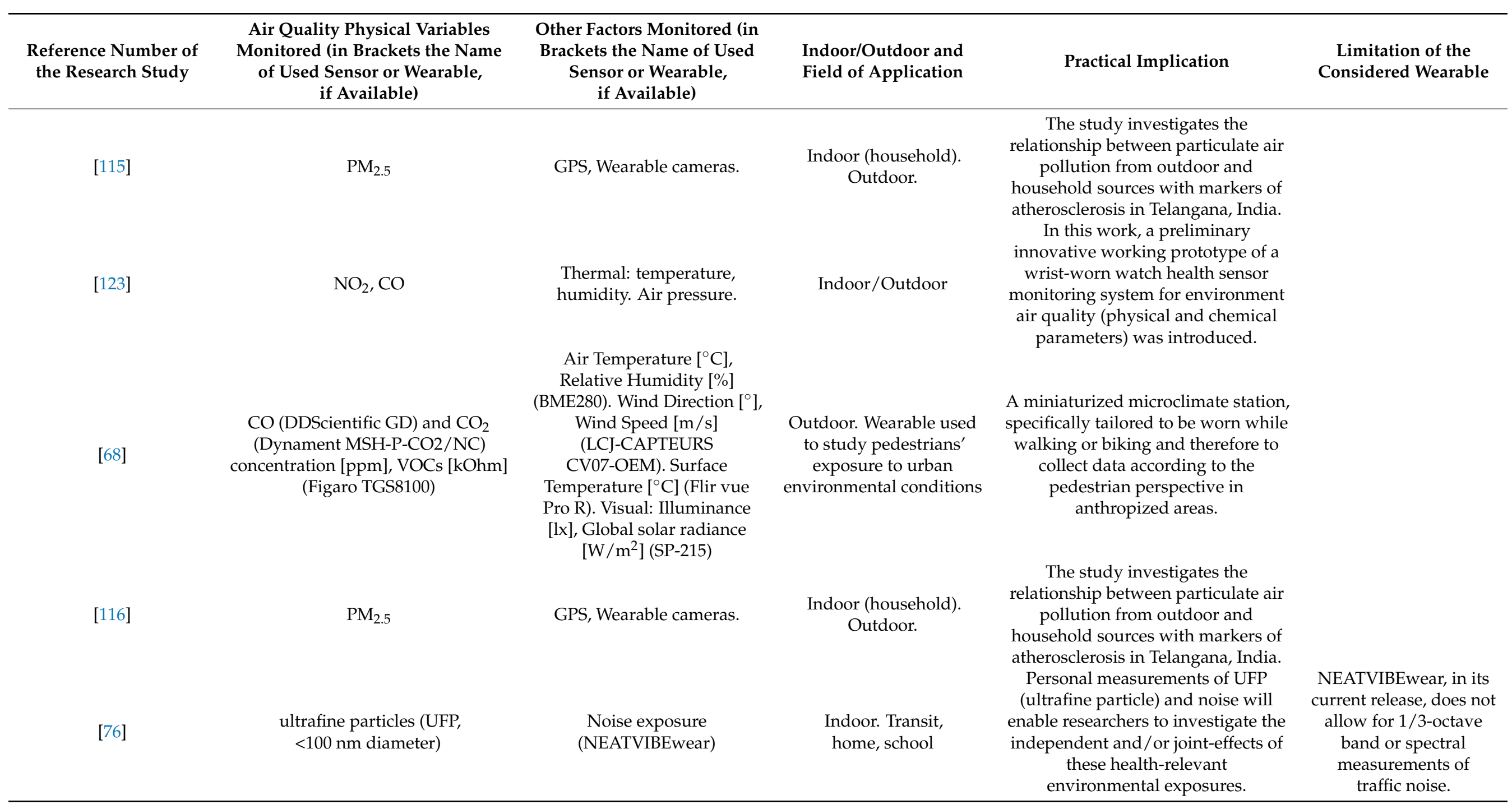


Table A4. Cont.

\begin{tabular}{|c|c|c|c|c|c|}
\hline $\begin{array}{l}\text { Reference Number of } \\
\text { the Research Study }\end{array}$ & $\begin{array}{c}\text { Air Quality Physical Variables } \\
\text { Monitored (in Brackets the Name } \\
\text { of Used Sensor or Wearable, } \\
\text { if Available) }\end{array}$ & $\begin{array}{l}\text { Other Factors Monitored (in } \\
\text { Brackets the Name of Used } \\
\text { Sensor or Wearable, } \\
\text { if Available) }\end{array}$ & $\begin{array}{l}\text { Indoor/Outdoor and } \\
\text { Field of Application }\end{array}$ & Practical Implication & $\begin{array}{l}\text { Limitation of the } \\
\text { Considered Wearable }\end{array}$ \\
\hline [108] & $\mathrm{CO}$ and $\mathrm{CO}_{2}$ (WE-Safe) & $\begin{array}{l}\text { Thermal: Air Temperature } \\
\text { and Relative humidity. } \\
\text { Visual: UV. (WE-Safe) } \\
\text { Thermal: Air Temperature } \\
\text { and Relative humidity. } \\
\text { Visual: UV, ambient light. }\end{array}$ & Indoor/Outdoor & $\begin{array}{l}\text { This paper presented a wearable for } \\
\text { people working in extreme and harsh } \\
\text { environments when they are not in } \\
\text { safe zones. Such an IoT platform will } \\
\text { present new opportunities for saving } \\
\text { lives or preventing health issues etc. } \\
\text { The aim of this study is to develop a } \\
\text { wearable environmental monitoring } \\
\text { system (WEMS), an IoT device, to } \\
\text { measure environmental variables. } \\
\text { Such an IoT platform will present } \\
\text { new opportunities for saving lives or } \\
\text { preventing health issues, etc. }\end{array}$ & \\
\hline [117] & $\begin{array}{c}\text { PM (with } 6 \text { particle size channels: } 0.3 \\
\mu \mathrm{m}, 0.5 \mu \mathrm{m}, 1.0 \mu \mathrm{m}, 2.5 \mu \mathrm{m}, 5.0 \mu \mathrm{m}, \\
10 \mu \mathrm{m})(\text { CEM DT-9881) }\end{array}$ & $\begin{array}{l}\text { Thermal: Air Temperature } \\
\text { and Relative humidity (CEM } \\
\text { DT-9881). Heart rate and the } \\
\text { cadence of walking or cycling } \\
\text { speed (Wahoo Fitness sensor } \\
\text { TICKR RUN). Subjective data } \\
\text { about the feelings of air } \\
\text { quality and the symptoms } \\
\text { (e.g., cough, sore throat, eye } \\
\text { itchiness, etc.) reported via } \\
\text { the smartphone App } \\
\text { CrowdAir }\end{array}$ & Outdoor & $\begin{array}{l}\text { The data collection operation and } \\
\text { data analysis results demonstrate the } \\
\text { feasibility of the adopted } \\
\text { methodology and the developed } \\
\text { platform to identify the correlations } \\
\text { among air quality indicators, } \\
\text { participants' subjective feelings of air } \\
\text { quality, physical activity status } \\
\text { measured by wearable sensors, and } \\
\text { reported symptoms. }\end{array}$ & \\
\hline [79] & $\begin{array}{c}\text { PM }_{2.5} \text { an } \text { PM }_{10} \\
\text { (PLANTOWER PM5003). }\end{array}$ & $\begin{array}{c}\text { Thermal: air humidity, } \\
\text { temperature (PLANTOWER } \\
\text { PM5003). Noise [db] } \\
\text { (LENA-Language } \\
\text { Environment } \\
\text { Analysis System) }\end{array}$ & Indoor. School, Home. & $\begin{array}{l}\text { Preliminary results indicate that it is } \\
\text { feasible to gather personal } \\
\text { Particulate Matter }\left(\mathrm{PM}_{2.5} \text { and } \mathrm{PM}_{10}\right), \\
\text { language, and noise data, cognitive } \\
\text { assessments, and biospecimens from } \\
\text { a sample of 3-4-year-old children. }\end{array}$ & \\
\hline
\end{tabular}


Table A4. Cont.

\begin{tabular}{|c|c|c|c|c|c|}
\hline $\begin{array}{l}\text { Reference Number of } \\
\text { the Research Study }\end{array}$ & $\begin{array}{c}\text { Air Quality Physical Variables } \\
\text { Monitored (in Brackets the Name } \\
\text { of Used Sensor or Wearable, } \\
\text { if Available) }\end{array}$ & $\begin{array}{l}\text { Other Factors Monitored (in } \\
\text { Brackets the Name of Used } \\
\text { Sensor or Wearable, } \\
\text { if Available) }\end{array}$ & $\begin{array}{l}\text { Indoor/Outdoor and } \\
\text { Field of Application }\end{array}$ & Practical Implication & $\begin{array}{l}\text { Limitation of the } \\
\text { Considered Wearable }\end{array}$ \\
\hline [90] & $\begin{array}{l}\text { Ozone, particulate matter, } \mathrm{CO} \\
\text { (EnviroSensor 2.0). }\end{array}$ & $\begin{array}{l}\text { Thermal: Temperature }\left[{ }^{\circ} \mathrm{C}\right] \\
\text { Relative Humidity [\%]. } \\
\text { Position: Latitude and } \\
\text { longitude (EnviroSensor 2.0). }\end{array}$ & Laboratory test & $\begin{array}{l}\text { Portable air quality sensors have the } \\
\text { potential to fill in the gap left by } \\
\text { traditional air pollution monitoring. }\end{array}$ & $\begin{array}{l}\text { Power draw of } \\
\text { the sensor }\end{array}$ \\
\hline [124] & $\mathrm{CO}_{2}(\mathrm{COZIR}-\mathrm{AJ}-5000)$ & $\begin{array}{l}\text { Thermal: Temperature }\left[{ }^{\circ} \mathrm{C}\right] \\
\text { Relative Humidity [\%] } \\
(\mathrm{SHT} 21) \text {. Air pressure } \\
\text { (BMP180). Acceleration and } \\
\text { angular velocity (MPU-6050). }\end{array}$ & Indoor/Outdoor & $\begin{array}{l}\text { The device capability has been } \\
\text { assessed using a testing strategy that } \\
\text { included three scenarios: indoor } \\
\text { measurements, outdoor } \\
\text { measurements, and indoor-outdoor } \\
\text { measurements. It has shown } \\
\text { promising results and a good match } \\
\text { with the values found in } \\
\text { the literature. }\end{array}$ & \\
\hline
\end{tabular}


Table A4. Cont.

\begin{tabular}{|c|c|c|c|c|c|}
\hline $\begin{array}{l}\text { Reference Number of } \\
\text { the Research Study }\end{array}$ & $\begin{array}{c}\text { Air Quality Physical Variables } \\
\text { Monitored (in Brackets the Name } \\
\text { of Used Sensor or Wearable, } \\
\text { if Available) }\end{array}$ & $\begin{array}{l}\text { Other Factors Monitored (in } \\
\text { Brackets the Name of Used } \\
\text { Sensor or Wearable, } \\
\text { if Available) }\end{array}$ & $\begin{array}{l}\text { Indoor/Outdoor and } \\
\text { Field of Application }\end{array}$ & Practical Implication & $\begin{array}{l}\text { Limitation of the } \\
\text { Considered Wearable }\end{array}$ \\
\hline [91] & $\mathrm{CO}_{2}[\mathrm{ppm}]$ & $\begin{array}{c}\text { Temperature }\left[{ }^{\circ} \mathrm{C}\right], \text { Relative } \\
\text { Humidity }[\%](\mathrm{SHT} 11)\end{array}$ & Indoor. & $\begin{array}{l}\text { This indoor smart environment } \\
\text { monitoring system for safety } \\
\text { applications is based on custom } \\
\text { wearable sensor nodes, connected to } \\
\text { a static WSN. The system has been } \\
\text { developed for a hazardous gas } \\
\text { environment, but could be applied to } \\
\text { a number of other safety applications } \\
\text { or in other areas such as the tracking } \\
\text { of medical devices in a hospital. }\end{array}$ & \\
\hline [92] & Ozone. & $\begin{array}{c}\text { Thermal: Temperature }\left[{ }^{\circ} \mathrm{C}\right] \text {, } \\
\text { Relative Humidity }[\%] . \\
\text { Biometric parameters: Herat } \\
\text { rate, respiratory rate and } \\
\text { expiratory airflow, skin } \\
\text { impedance. Acceleration. }\end{array}$ & Indoor. & $\begin{array}{c}\text { The system consists of a wristband, a } \\
\text { chest patch, and a } \\
\text { handheld spirometer. }\end{array}$ & \\
\hline [103] & VOCs (Figaro TG2620 sensor) & $\begin{array}{c}\text { Thermal: Temperature }\left[{ }^{\circ} \mathrm{C}\right] \\
\text { Relative Humidity }[\%] .\end{array}$ & $\begin{array}{l}\text { Outdoor. } \\
\text { Outdoor. }\end{array}$ & $\begin{array}{l}\text { The author reports the design and } \\
\text { initial deployment of the Citisense } \\
\text { mobile air quality sensing system. } \\
\text { The authors presented WearAir, an } \\
\text { expressive T-shirt to sense the } \\
\text { surrounding air quality, as indicated } \\
\text { by the measured volatile organic } \\
\text { compounds. It can motivate others to } \\
\text { study ways to convey environmental } \\
\text { information more effectively. }\end{array}$ & \\
\hline
\end{tabular}


Table A4. Cont.

\begin{tabular}{cc}
\hline $\begin{array}{c}\text { Reference Number of } \\
\text { the Research Study }\end{array}$ & $\begin{array}{c}\text { Monitored (in Brackets the Name } \\
\text { of Used Sensor or Wearable, } \\
\text { if Available) }\end{array}$
\end{tabular}
if Available)

\author{
$\mathrm{PM}_{2.5}$ (RTI MicroPEM v3.2b)
}

Polycyclic aromatic

hydrocarbons-PAHs, oxygenated PAHs-OPAHs, Polychlorinated biphenyls-PCBs, Pesticides, organophophorous flame retardants-OPFRs. (MyExposome). Surface ozone content-SOC (2BTech Personal Ozone Monitor)
$\mathrm{CO}$ and $\mathrm{NO}_{2}$

Other Factors Monitored (in

Brackets the Name of Used

Sensor or Wearable if Available)

Thermal: Temperature $\left[{ }^{\circ} \mathrm{C}\right]$, Relative Humidity [\%]

Acceleration. (RTI

MicroPEM v3.2b).

Thermal: Air Temperature and relative humidity (Model

HTR-170). Visual: UV (UV dosimeter badge).

Thermal: air humidity,

temperature. Acoustic:

Sound pressure level $[\mathrm{db}$

(MLMS-EMGN-4.0).
Indoor/Outdoor and

Field of Application

Practical Implication

Limitation of the

Considered Wearable
Authors developed a machine learning model for identifying periods of bicycling activity using passively collected data from the MicroPEM wearable. This finding helps strengthen the case for using wearable monitors in exposure assessment studies, as it becomes possible to estimate potential inhaled doses if personal exposure data is combined with respiration rate.

Polycyclic aromatic hydrocarbons $(\mathrm{PAH})$ indicate possible causes of hair damages. This is the first meteorotropic study of its kind, combining environmental aggressors related to hair damage, opening new research hypothesis further studies on exposome.

This device measures several physical and chemical environmental parameters that are known to be hazardous. 
Table A4. Cont.

\begin{tabular}{|c|c|c|c|c|c|}
\hline $\begin{array}{l}\text { Reference Number of } \\
\text { the Research Study }\end{array}$ & $\begin{array}{c}\text { Air Quality Physical Variables } \\
\text { Monitored (in Brackets the Name } \\
\text { of Used Sensor or Wearable, } \\
\text { if Available) }\end{array}$ & $\begin{array}{l}\text { Other Factors Monitored (in } \\
\text { Brackets the Name of Used } \\
\text { Sensor or Wearable, } \\
\text { if Available) }\end{array}$ & $\begin{array}{l}\text { Indoor/Outdoor and } \\
\text { Field of Application }\end{array}$ & Practical Implication & $\begin{array}{l}\text { Limitation of the } \\
\text { Considered Wearable }\end{array}$ \\
\hline [75] & $\mathrm{NO}_{2}, \mathrm{CO}$ & $\begin{array}{l}\text { Acoustic: Sound level [db]. } \\
\text { Thermal: air temperature and } \\
\text { relative humidity. UV. } \\
\text { Biometrics: skin temperature, } \\
\text { heart rate. Motion activity (9 } \\
\text { Degree of Freedom(DoF)) } \\
\text { motion tracking by } \\
\text { accelerometer, gyroscope } \\
\text { and magnetometer. }\end{array}$ & Indoor/Outdoor & $\begin{array}{l}\text { Wrist-worn devices can integrate } \\
\text { parameters from the environmental, } \\
\text { behavioral, and } \\
\text { physiological domains. }\end{array}$ & \\
\hline [78] & $\begin{array}{l}\text { Styrene exposure derived by } \\
\text { biological monitoring in saliva } \\
\text { and urine }\end{array}$ & Noise levels (Quest DLX-1) & $\begin{array}{l}\text { Indoor. Workers } \\
\text { employed in molding and } \\
\text { in artifacts refining }\end{array}$ & $\begin{array}{l}\text { A significant negative correlation } \\
\text { was found between otoacoustic } \\
\text { emission levels and the concentration } \\
\text { of the styrene exposure. }\end{array}$ & \\
\hline
\end{tabular}




\section{References}

1. Marques, G.; Pitarma, R. mHealth: Indoor Environmental Quality Measuring System for Enhanced Health and Well-Being Based on Internet of Things. J. Sens. Actuator Netw. 2019, 8, 43. [CrossRef]

2. Xia, F.; Yang, L.T.; Wang, L.; Vinel, A. Internet of Things. Int. J. Commun. Syst. 2012, 25, 1101-1102. [CrossRef]

3. Gubbi, J.; Buyya, R.; Marusic, S.; Palaniswami, M. Internet of Things (IoT): A vision, architectural elements, and future directions. Futur. Gener. Comput. Syst. 2013, 29, 3028-3043. [CrossRef]

4. Lee, G.M.; Crespi, N.; Choi, J.K.; Boussard, M. Internet of Things. In Transactions on Petri Nets and Other Models of Concurrency XV; Springer Science and Business Media LLC: Berlin/Heidelberg, Germany, 2013; pp. 257-282.

5. Atzori, L.; Iera, A.; Morabito, G. The Internet of Things: A survey. Comput. Netw. 2010, 54, 2787-2805. [CrossRef]

6. Lamonaca, F.; Polimeni, G.; Barbé, K.; Grimaldi, D. Health parameters monitoring by smartphone for quality of life improvement. Measurement 2015, 73, 82-94. [CrossRef]

7. Montoliu, R.; Blom, J.; Gatica-Perez, D. Discovering places of interest in everyday life from smartphone data. Multimedia Tools Appl. 2012, 62, 179-207. [CrossRef]

8. $\quad$ Lachmann, B.; Sindermann, C.; Sariyska, R.Y.; Luo, R.; Melchers, M.C.; Becker, B.; Cooper, A.; Montag, C. The Role of Empathy and Life Satisfaction in Internet and Smartphone Use Disorder. Front. Psychol. 2018, 9, 398. [CrossRef] [PubMed]

9. Zhao, S.; Li, S.; Ramos, J.; Luo, Z.; Jiang, Z.; Dey, A.K.; Pan, G. User profiling from their use of smartphone applications: A survey. Pervas. Mob. Comput. 2019, 59, 101052. [CrossRef]

10. Sama, R. Impact of Media Advertisements on Consumer Behaviour. J. Creat. Commun. 2019, 14, 54-68. [CrossRef]

11. Jung, Y.; Kim, S.; Choi, B. Consumer valuation of the wearables: The case of smartwatches. Comput. Hum. Behav. 2016, 63, 899-905. [CrossRef]

12. Peake, J.M.; Kerr, G.; Sullivan, J.P. A critical review of consumer wearables, mobile applications, and equipment for providing biofeedback, monitoring stress, and sleep in physically active populations. Front. Physiol. 2018, 9, 743. [CrossRef]

13. Stefana, E.; Marciano, F.; Rossi, D.; Cocca, P.; Tomasoni, G. Wearable Devices for Ergonomics: A Systematic Literature Review. Sensors 2021, 21, 777. [CrossRef]

14. Kristoffersson, A.; Lindén, M. A Systematic Review on the Use of Wearable Body Sensors for Health Monitoring: A Qualitative Synthesis. Sensors 2020, 20, 1502. [CrossRef]

15. Lu, L.; Zhang, J.; Xie, Y.; Gao, F.; Xu, S.; Wu, X.; Ye, Z. Wearable Health Devices in Health Care: Narrative Systematic Review. JMIR mHealth uHealth 2020, 8, e18907. [CrossRef]

16. Khakurel, J.; Melkas, H.; Porras, J. Tapping into the wearable device revolution in the work environment: A systematic review. Inf. Technol. People 2018, 31, 791-818. [CrossRef]

17. Svertoka, E.; Saafi, S.; Rusu-Casandra, A.; Burget, R.; Marghescu, I.; Hosek, J.; Ometov, A. Wearables for Industrial Work Safety: A Survey. Sensors 2021, 21, 3844. [CrossRef]

18. Morawska, L.; Thai, P.K.; Liu, X.; Asumadu-Sakyi, A.; Ayoko, G.; Bartonova, A.; Bedini, A.; Chai, F.; Christensen, B.; Dunbabin, M.; et al. Applications of low-cost sensing technologies for air quality monitoring and exposure assessment: How far have they gone? Environ. Int. 2018, 116, 286-299. [CrossRef]

19. Singla, S.; Bansal, D.; Misra, A.; Raheja, G. Towards an integrated framework for air quality monitoring and exposure estimationA review. Environ. Monit. Assess. 2018, 190, 562. [CrossRef]

20. Borghi, F.; Spinazzè, A.; Rovelli, S.; Campagnolo, D.; Del Buono, L.; Cattaneo, A.; Cavallo, D.M. Miniaturized Monitors for Assessment of Exposure to Air Pollutants: A Review. Int. J. Environ. Res. Public Health 2017, 14, 909. [CrossRef]

21. Kumar, A.; Kim, H.; Hancke, G.P. Environmental Monitoring Systems: A Review. IEEE Sens. J. 2013, 13, 1329-1339. [CrossRef]

22. Al Mamun, A.; Yuce, M.R. Sensors and Systems for Wearable Environmental Monitoring Toward IoT-Enabled Applications: A Review. IEEE Sens. J. 2019, 19, 7771-7788. [CrossRef]

23. Coulby, G.; Clear, A.; Jones, O.; Godfrey, A. A Scoping Review of Technological Approaches to Environmental Monitoring. Int. J. Environ. Res. Public Health 2020, 17, 3995. [CrossRef] [PubMed]

24. Bass, T. The Eudaemonic Pie; Houghton Mifflin Harcourt: Boston, MA, USA, 1985.

25. Mann, S. Wearable computing: A first step toward personal imaging. Computer 1997, 30, 25-32. [CrossRef]

26. Starner, T. Human-powered wearable computing. IBM Syst. J. 1996, 35, 618-629. [CrossRef]

27. Picard, R.W. Affective Wearables. Affect. Comput. 2000, 90-97. [CrossRef]

28. Gao, W.; Emaminejad, S.; Nyein, H.Y.Y.; Challa, S.; Chen, K.; Peck, A.; Fahad, H.M.; Ota, H.; Shiraki, H.; Kiriya, D.; et al. Fully integrated wearable sensor arrays for multiplexed in situ perspiration analysis. Nat. Cell Biol. 2016, 529, 509-514. [CrossRef]

29. Lee, J.; Kim, D.; Ryoo, H.-Y.; Shin, B.-S. Sustainable Wearables: Wearable Technology for Enhancing the Quality of Human Life. Sustainability 2016, 8, 466. [CrossRef]

30. Palmer, B.; Gershbein, D. Wearables for Good: Use Case Handbook, Unicef. 2012, pp. 17-20. Available online: https://www. unicef.org/innovation/media/1416/file/Wearablesforgood.pdf (accessed on 9 June 2021).

31. Seneviratne, S.; Hu, Y.; Nguyen, T.; Lan, G.; Khalifa, S.; Thilakarathna, K.; Hassan, M.; Seneviratne, A. A Survey of Wearable Devices and Challenges. IEEE Commun. Surv. Tutor. 2017, 19, 2573-2620. [CrossRef] 
32. Düking, P.; Giessing, L.; Frenkel, M.O.; Koehler, K.; Holmberg, H.-C.; Sperlich, B. Wrist-Worn Wearables for Monitoring Heart Rate and Energy Expenditure While Sitting or Performing Light-to-Vigorous Physical Activity: Validation Study. JMIR $m H e a l t h$ uHealth 2020, 8, e16716. [CrossRef]

33. Klepeis, N.E.; Nelson, W.C.; Ott, W.R.; Robinson, J.P.; Tsang, A.M.; Switzer, P.; Behar, J.V.; Hern, S.C.; Engelmann, W.H. The National Human Activity Pattern Survey (NHAPS): A resource for assessing exposure to environmental pollutants. J. Expo. Sci. Environ. Epidemiol. 2001, 11, 231-252. [CrossRef]

34. Mohamed, M.F.; Raman, S.N.; Pratama, T.M.I.; Yusoff, W.F.M. Outdoor Environment of Low-cost Housing: A case study of Flat Taman Desa Sentosa. E3S Web Conf. 2014, 3, 01005. [CrossRef]

35. Clarke, J.; Allard, F.; La Rochelle, Ł.D. Workplace productivity and individual thermal satisfaction. Build. Environ. $2009,91,7001$.

36. Kleerekoper, L.; Esch, M.P.-V.; Salcedo, T.B. How to make a city climate-proof, addressing the urban heat island effect. Resour. Conserv. Recycl. 2012, 64, 30-38. [CrossRef]

37. Jones, A. Indoor air quality and health. Atmos. Environ. 1999, 33, 4535-4564. [CrossRef]

38. Lee, S.; Chang, M. Indoor and outdoor air quality investigation at schools in Hong Kong. Chemosphere 2000, 41, 109-113. [CrossRef]

39. Hwang, T.; Kim, J.T. Effects of indoor lighting on occupants' visual comfort and eye health in a green building. Indoor Built Environ. 2011, 20, 75-90. [CrossRef]

40. Brown, A.; Gjestland, T.; Dubois, D. Acoustic Environments and Soundscapes. In Soundscape and the Built Environment; CRC Press: Boca Raton, FL, USA, 2016; pp. 1-16.

41. Basner, M.; Babisch, W.; Davis, A.; Brink, M.; Clark, C.; Janssen, S.; Stansfeld, S. Auditory and non-auditory effects of noise on health. Lancet 2014, 383, 1325-1332. [CrossRef]

42. Stansfeld, S.A. Environmental noise guidelines for the european region. Proc. Inst. Acoust. 2019, 41, 17-20. Available online: https:/ / www.euro.who.int/en/publications/abstracts/environmental-noise-guidelines-for-the-european-region-2018 (accessed on 9 June 2021).

43. Masullo, M.; Maffei, L.; Sorrentino, F.; Ruggiero, G.; Rapuano, M. Effects of fan coils noise on cognitive performances in offices. In Proceedings of the 25th International Congress on Sound and Vibration (ICSV25), Hiroshima, Japan, 8-12 July 2018.

44. Puyana-Romero, V.; Lopez-Segura, L.S.; Maffei, L.; Hernández-Molina, R.; Masullo, M. Interactive Soundscapes: $360^{\circ}$-Video Based Immersive Virtual Reality in a Tool for the Participatory Acoustic Environment Evaluation of Urban Areas. Acta Acust. United Acust. 2017, 103, 574-588. [CrossRef]

45. Cho, H. Personal Environmental Monitoring System and network platform. In Proceedings of the 20159 th International Conference on Sensing Technology (ICST), Auckland, New Zealand, 8-10 December 2015; pp. 751-756.

46. Falagas, M.E.; Pitsouni, E.I.; Malietzis, G.; Pappas, G. Comparison of PubMed, Scopus, Web of Science, and Google Scholar: Strengths and weaknesses. FASEB J. 2007, 22, 338-342. [CrossRef]

47. Scopus Search Guide. Available online: http://schema.elsevier.com/dtds/document/bkapi/search/SCOPUSSearchTips.htm (accessed on 9 June 2021).

48. Uddin, S.; Khan, A. The impact of author-selected keywords on citation counts. J. Inf. 2016, 10, 1166-1177. [CrossRef]

49. Campedelli, G.M. Where are we? Using Scopus to map the literature at the intersection between artificial intelligence and research on crime. J. Comput. Soc. Sci. 2020, 1-28. [CrossRef]

50. Choi, J.; Yi, S.; Lee, K.C. Analysis of keyword networks in MIS research and implications for predicting knowledge evolution. Inf. Manag. 2011, 48, 371-381. [CrossRef]

51. Smith, J.; Noble, H. Bias in research: Table 1. Évid. Based Nurs. 2014, 17, 100-101. [CrossRef]

52. Buscemi, N.; Hartling, L.; Vandermeer, B.; Tjosvold, L.; Klassen, T. Single data extraction generated more errors than double data extraction in systematic reviews. J. Clin. Epidemiol. 2006, 59, 697-703. [CrossRef]

53. Bidwell, S.; Chalmers, S.I.; Clarke, M.; Crosbie, G.; Eastwood, A.; Fry-smith, A.; Harbour, R.; Lewis, R. Undertaking Systematic Reviews of Research on Effectiveness CRD's Guidance for those Carrying Out or Commissioning Reviews. CRD Rep. Number 4 2nd Ed. 4. 2001, p. 152. Available online: http:/ / opensigle.inist.fr/handle/10068/534964 (accessed on 9 June 2021).

54. Page, M.J.; McKenzie, J.E.; Bossuyt, P.M.; Boutron, I.; Hoffmann, T.C.; Mulrow, C.D.; Shamseer, L.; Tetzlaff, J.M.; Akl, E.A.; Brennan, S.E.; et al. The PRISMA 2020 statement: An updated guideline for reporting systematic reviews. Syst. Rev. 2021, 10, 1-11. [CrossRef]

55. Bierman, A.; Klein, T.R.; Rea, M.S. The Daysimeter: A device for measuring optical radiation as a stimulus for the human circadian system. Meas. Sci. Technol. 2005, 16, 2292-2299. [CrossRef]

56. Rea, M.S.; Figueiro, M.G.; Bullough, J.D.; Bierman, A. A model of phototransduction by the human circadian system. Brain Res. Rev. 2005, 50, 213-228. [CrossRef]

57. Miller, D.; Bierman, A.; Figueiro, M.; Schernhammer, E.; Rea, M. Ecological measurements of light exposure, activity and circadian disruption. Light. Res. Technol. 2010, 42, 271-284. [CrossRef]

58. Figueiro, M.G.; Plitnick, B.; Rea, M.S. The effects of chronotype, sleep schedule and light/dark pattern exposures on circadian phase. Sleep Med. 2014, 15, 1554-1564. [CrossRef]

59. Figueiro, M.G.; Hamner, R.; Bierman, A.; Rea, M.S. Comparisons of three practical field devices used to measure personal light exposures and activity levels. Light. Res. Technol. 2013, 45, 421-434. [CrossRef] [PubMed] 
60. Figueiro, M.; Kalsher, M.; Steverson, B.; Heerwagen, J.; Kampschroer, K.; Rea, M. Circadian-effective light and its impact on alertness in office workers. Light. Res. Technol. 2018, 51, 171-183. [CrossRef]

61. Figueiro, M.G.; Hunter, C.M.; Higgins, P.A.; Hornick, T.R.; Jones, G.; Plitnick, B.; Brons, J.; Rea, M.S. Tailored lighting intervention for persons with dementia and caregivers living at home. Sleep Health 2015, 1, 322-330. [CrossRef] [PubMed]

62. Figueiro, M.G. Individually tailored light intervention through closed eyelids to promote circadian alignment and sleep health. Sleep Health 2015, 1, 75-82. [CrossRef]

63. Figueiro, M.G.; Plitnick, B.A.; Lok, A.; Jones, G.; Higgins, P.; Hornick, T.R.; Rea, M.S. Tailored lighting intervention improves measures of sleep, depression, and agitation in persons with Alzheimer's disease and related dementia living in long-term care facilities. Clin. Interv. Aging 2014, 9, 1527-1537. [CrossRef]

64. Jardim, A.C.N.; Pawley, M.D.M.; Cheeseman, J.F.; Guesgen, M.J.; Steele, C.T.; Warman, G.R. Validating the Use of Wrist-Level Light Monitoring for In-Hospital Circadian Studies. Chrono Int. 2011, 28, 834-840. [CrossRef]

65. Figueiro, M.; Brons, J.; Plitnick, B.; Donlan, B.; Leslie, R.; Rea, M. Measuring circadian light and its impact on adolescents. Light. Res. Technol. 2010, 43, 201-215. [CrossRef]

66. Rea, M.S. Human health and well-being: Promises for a bright future from solid-state lighting. SPIE OPTO 2011, $7954,795404$. [CrossRef]

67. Higgins, P.A.; Hornick, T.R.; Figueiro, M.G. Rest-activity and light exposure patterns in the home setting: A methodological case study. Am. J. Alzheimers Dis. Other Demen. 2010, 25, 353-361. [CrossRef]

68. Pigliautile, I.; Pisello, A.L. A new wearable monitoring system for investigating pedestrians' environmental conditions: Development of the experimental tool and start-up findings. Sci. Total Environ. 2018, 630, 690-706. [CrossRef]

69. Fletcher, R.R.; Oreskovic, N.M.; Robinson, A.I. Design and clinical feasibility of personal wearable monitor for measurement of activity and environmental exposure. In Proceedings of the 2014 36th Annual International Conference of the IEEE Engineering in Medicine and Biology Society, Chicago, IL, USA, 26-30 August 2014.

70. Wei, Y.; Zhang, W.; Hou, C.; Zhang, Q.; Li, Y.; Wang, H. Independent dual-responsive Janus chromic fibers. Sci. China Mater. 2021, 64, 1770-1779. [CrossRef]

71. Rhudy, M.B.; Greenauer, N.; Mello, C. Wearable light data logger for studying physiological and psychological effects of light data. HardwareX 2020, 8, e00157. [CrossRef]

72. Haghi, M.; Thurow, K.; Stoll, N. Four-layer wrist worn device for sound level and hazardous gases environmental monitoring. In Proceedings of the 2017 2nd International Conference on System Reliability and Safety (ICSRS), Milan, Italy, 20-22 December 2017.

73. Haghi, M.; Stoll, R.; Thurow, K. A Low-Cost, Standalone, and Multi-Tasking Watch for Personalized Environmental Monitoring. IEEE Trans. Biomed. Circuits Syst. 2018, 12, 1144-1154. [CrossRef]

74. Haghi, M.; Thurow, K. Toward a New Approach in Wearable Devices in Safety Monitoring: Miniaturization and 3D Space Utilization. SLAS Technol. Transl. Life Sci. Innov. 2019, 24, 444-447. [CrossRef]

75. Haghi, M.; Danyali, S.; Thurow, K.; Warnecke, J.M.; Wang, J.; Deserno, T.M. Hardware Prototype for Wrist-Worn Simultaneous Monitoring of Environmental, Behavioral, and Physiological Parameters. Appl. Sci. 2020, 10, 5470. [CrossRef]

76. Leaffer, D.; Wolfe, C.; Doroff, S.; Gute, D.; Wang, G.; Ryan, P. Wearable Ultrafine Particle and Noise Monitoring Sensors Jointly Measure Personal Co-Exposures in a Pediatric Population. Int. J. Environ. Res. Public Health 2019, 16, 308. [CrossRef]

77. Guerrache, F.; Younis, E.M.G.; Kanjo, E. Quantifying Environmental Noise impact on Heart Rate Variability. In Proceedings of the 8th EAI International Conference on Mobile Computing, Applications and Services, Cambridge, UK, 30 November-1 December 2016. [CrossRef]

78. Sisto, R.; Cerini, L.; Gatto, M.P.; Gherardi, M.; Gordiani, A.; Sanjust, F.; Paci, E.; Tranfo, G.; Moleti, A. Otoacoustic emission sensitivity to exposure to styrene and noise. J. Acoust. Soc. Am. 2013, 134, 3739-3748. [CrossRef]

79. Schultz, A.A.; Malecki, K.M.; Olson, M.M.; Selman, S.B.; Olaiya, O.-I.; Spicer, A.; Schauer, J.J.; Edwards, R.; Kirkorian, H.L.; Dilworth-Bart, J. Investigating Cumulative Exposures among 3- to 4-Year-Old Children Using Wearable Ultrafine Particle Sensors and Language Environment Devices: A Pilot and Feasibility Study. Int. J. Environ. Res. Public Health 2020, 17, 5259. [CrossRef]

80. Hernandez-Jayo, U.; Goñi, A. Zaratamap: Noise Characterization in the Scope of a Smart City through a Low Cost and Mobile Electronic Embedded System. Sensors 2021, 21, 1707. [CrossRef]

81. Frampton, T.H.; Tiele, A.; Covington, J.A. Development of a Personalised Environmental Quality Monitoring System (PONG). IEEE Sens. J. 2021, 21, 15230-15236. [CrossRef]

82. Pioppi, B.; Pigliautile, I.; Pisello, A.L. Data collected by coupling fix and wearable sensors for addressing urban microclimate variability in an historical Italian city. Data Brief 2020, 29, 105322. [CrossRef]

83. Zeng, S.; Sun, H.; Park, C.; Zhang, M.; Zhu, M.; Yan, M.; Chov, N.; Li, E.; Smith, A.T.; Xu, G.; et al. Multi-stimuli responsive chromism with tailorable mechanochromic sensitivity for versatile interactive sensing under ambient conditions. Mater. Horizons 2019, 7, 164-172. [CrossRef]

84. De Vecchi, R.; Ripper, J.D.S.C.; Roy, D.; Breton, L.; Marciano, A.G.; De Souza, P.M.B.; Corrêa, M.D.P. Using wearable devices for assessing the impacts of hair exposome in Brazil. Sci. Rep. 2019, 9, 1-10. [CrossRef]

85. Wang, S.; Richardson, M.B.; Wu, C.Y.; Cholewa, C.D.; Lungu, C.T.; Zaitchik, B.; Gohlke, J.M. Estimating Occupational Heat Exposure From Personal Sampling of Public Works Employees in Birmingham, Alabama. J. Occup. Environ. Med. 2019, 61, 518-524. [CrossRef] 
86. Wu, F.; Redoute, J.-M.; Yuce, M.R. A Self-Powered Wearable Body Sensor Network System for Safety Applications. In Proceedings of the 2018 IEEE Sensors Applications Symposium (SAS), New Delhi, India, 28-31 October 2018.

87. Hao, L.; Ding, J.; Yuan, N.; Xu, J.; Zhou, X.; Dai, S.; Chen, B. Visual and flexible temperature sensor based on a pectin-xanthan gum blend film. Org. Electron. 2018, 59, 243-246. [CrossRef]

88. Spirjakin, D.; Baranov, A.; Akbari, S. Wearable Wireless Sensor System With RF Remote Activation for Gas Monitoring Applications. IEEE Sens. J. 2018, 18, 2976-2982. [CrossRef]

89. Sahatiya, P.; Kadu, A.; Gupta, H.; Gomathi, P.T.; Badhulika, S. Flexible, Disposable Cellulose-Paper-Based $\mathrm{MoS}_{2} / \mathrm{Cu}_{2} \mathrm{~S}$ Hybrid for Wireless Environmental Monitoring and Multifunctional Sensing of Chemical Stimuli. ACS Appl. Mater. Interfaces 2018, 10, 9048-9059. [CrossRef]

90. Dam, N.; Ricketts, A.; Catlett, B.; Henriques, J. Wearable sensors for analyzing personal exposure to air pollution. In Proceedings of the 2017 Systems and Information Engineering Design Symposium (SIEDS), Charlottesville, VA, USA, 28 April 2017.

91. Antolín, D.; Medrano, N.; Calvo, B.; Pérez, F. A Wearable Wireless Sensor Network for Indoor Smart Environment Monitoring in Safety Applications. Sensors 2017, 17, 365. [CrossRef]

92. Dieffenderfer, J.; Goodell, H.; Mills, S.; McKnight, M.; Yao, S.; Lin, F.; Beppler, E.; Bent, B.; Lee, B.; Misra, V.; et al. Low-Power Wearable Systems for Continuous Monitoring of Environment and Health for Chronic Respiratory Disease. IEEE J. Biomed. Health Inform. 2016, 20, 1251-1264. [CrossRef]

93. Tian, R.; Dierk, C.; Myers, C.; Paulos, E. MyPart. In Proceedings of the 2016 CHI Conference on Human Factors in Computing Systems, San Jose, CA, USA, 7-12 May 2016.

94. Nakayoshi, M.; Kanda, M.; Shi, R.; De Dear, R. Outdoor thermal physiology along human pathways: A study using a wearable measurement system. Int. J. Biometeorol. 2015, 59, 503-515. [CrossRef]

95. Bales, E.; Nikzad, N.; Quick, N.; Ziftci, C.; Patrick, K.; Griswold, W. Citisense: Mobile Air Quality Sensing for Individuals and Communities. Design and deployment of the Citisense mobile air-quality system. In Proceedings of the 6th International Conference on Pervasive Computing Technologies for Healthcare, San Diego, CA, USA, 21-24 May 2012.

96. Shum, L.V.; Rajalakshmi, P.; Afonja, A.; McPhillips, G.; Binions, R.; Cheng, L.; Hailes, S. On the Development of a Sensor Module for Real-Time Pollution Monitoring. In Proceedings of the 2011 International Conference on Information Science and Applications, Jeju Island, Korea, 26-29 April 2010.

97. Volckens, J.; Quinn, C.; Leith, D.; Mehaffy, J.; Henry, C.; Miller-Lionberg, D. Development and evaluation of an ultrasonic personal aerosol sampler. Indoor Air 2016, 27, 409-416. [CrossRef] [PubMed]

98. Butca, C.G.; Suciu, G.; Ochian, A.; Fratu, O.; Halunga, S. Wearable sensors and cloud platform for monitoring environmental parameters in e-health applications. In Proceedings of the 2014 11th International Symposium on Electronics and Telecommunications (ISETC), Timisoara, Romania, 14-15 November 2014.

99. U.S. Environmental Protection Agency, Indoor Air Quality-Building Assessment Survey and Evaluation (BASE) Study. Available online: http: / / www.epa.gov/iaq/base/index.html (accessed on 9 June 2021).

100. US EPA, OAR, ORIA, Volatile Organic Compounds' Impact on Indoor Air Quality, Epa. (2018) 1. Available online: https: //www.epa.gov/indoor-air-quality-iaq/volatile-organic-compounds-impact-indoor-air-quality (accessed on 9 June 2021).

101. Rajapakse, M.Y.; Borras, E.; Fung, A.G.; Yeap, D.; McCartney, M.M.; Fabia, F.M.; Kenyon, N.J.; Davis, C.E. An environmental air sampler to evaluate personal exposure to volatile organic compounds. Analyst 2021, 146, 636-645. [CrossRef] [PubMed]

102. Fung, A.G.; Rajapakse, M.Y.; McCartney, M.; Falcon, A.K.; Fabia, F.M.; Kenyon, N.J.; Davis, C.E. Wearable Environmental Monitor To Quantify Personal Ambient Volatile Organic Compound Exposures. ACS Sens. 2019, 4, 1358-1364. [CrossRef] [PubMed]

103. Kim, S.; Paulos, E.; Gross, M.D. WearAir. In Proceedings of the Fourth International Conference on Animal-Computer Interaction, Cambridge, MA, USA, 24-27 January 2010.

104. Tsow, F.; Forzani, E.; Rai, A.; Wang, R.; Tsui, R.; Mastroianni, S.; Knobbe, C.; Gandolfi, A.J.; Tao, N.J. A Wearable and Wireless Sensor System for Real-Time Monitoring of Toxic Environmental Volatile Organic Compounds. IEEE Sens. J. 2009, 9, 1734-1740. [CrossRef]

105. Deng, Y.; Chen, C.; Xian, X.; Tsow, F.; Verma, G.; McConnell, R.; Fruin, S.; Tao, N.; Forzani, E.S. A Novel Wireless Wearable Volatile Organic Compound (VOC) Monitoring Device with Disposable Sensors. Sensors 2016, 16, 2060. [CrossRef]

106. Chen, C.; Tsow, F.; Xian, X.; Forzani, E.; Tao, N.; Tsui, R. A Wearable Sensing System for Assessment of Exposures to Environmental Volatile Organic Compounds. Adv. Struct. Saf. Stud. 2015, 1256, 201-211. [CrossRef]

107. Mallires, K.R.; Wang, D.; Tipparaju, V.V.; Tao, N. Developing a Low-Cost Wearable Personal Exposure Monitor for Studying Respiratory Diseases Using Metal-Oxide Sensors. IEEE Sens. J. 2019, 19, 8252-8261. [CrossRef]

108. Cho, H. Design and Implementation of a Wearable Environmental Monitoring System. In Proceedings of the 2015 Workshop on ns-3, Florence, Italy, 18 May 2015.

109. Agency, E.P. Particulate Matter (PM) Pollution, Webpage. (2018) 1. Available online: https://www.epa.gov/pm-pollution/ particulate-matter-pm-basics\#PM (accessed on 9 June 2021).

110. Pillarisetti, A.; Carter, E.; Rajkumar, S.; Young, B.N.; Benka-Coker, M.L.; Peel, J.L.; Johnson, M.; Clark, M. Measuring personal exposure to fine particulate matter (PM2.5) among rural Honduran women: A field evaluation of the Ultrasonic Personal Aerosol Sampler (UPAS). Environ. Int. 2019, 123, 50-53. [CrossRef]

111. Kao, M.C.; Lung, S.C. Personal particulate exposures in Buddhist temples. Chin. J. Public Health 2000, 19, 138-143. [CrossRef] 
112. Hojaiji, H.; Goldstein, O.; King, C.E.; Sarrafzadeh, M.; Jerrett, M. Design and calibration of a wearable and wireless research grade air quality monitoring system for real-time data collection. In Proceedings of the 2017 IEEE Global Humanitarian Technology Conference (GHTC), San Jose, CA, USA, 19-22 October 2017.

113. Assimakopoulos, V.; Bekiari, T.; Pateraki, S.; Maggos, T.; Stamatis, P.; Nicolopoulou, P.; Assimakopoulos, M. Assessing personal exposure to PM using data from an integrated indoor-outdoor experiment in Athens-Greece. Sci. Total Environ. 2018, 636, 1303-1320. [CrossRef]

114. Gilliland, J.; Maltby, M.; Xu, X.; Luginaah, I.; Loebach, J.; Shah, T. Is active travel a breath of fresh air? Examining children's exposure to air pollution during the school commute. Spat. Spatio-Temporal Epidemiol. 2019, 29, 51-57. [CrossRef]

115. Tonne, C.; Salmon, M.; Sanchez, M.; Sreekanth, V.; Bhogadi, S.; Sambandam, S.; Balakrishnan, K.; Kinra, S.; Marshall, J.D Integrated assessment of exposure to PM2.5 in South India and its relation with cardiovascular risk: Design of the CHAI observational cohort study. Int. J. Hyg. Environ. Health 2017, 220, 1081-1088. [CrossRef]

116. Milà, C.; Salmon, M.; Sanchez, M.; Ambrós, A.; Bhogadi, S.; Sreekanth, V.; Nieuwenhuijsen, M.; Kinra, S.; Marshall, J.D.; Tonne, C. When, Where, and What? Characterizing Personal PM2.5Exposure in Periurban India by Integrating GPS, Wearable Camera, and Ambient and Personal Monitoring Data. Environ. Sci. Technol. 2018, 52, 13481-13490. [CrossRef]

117. Yang, B.; Castell, N.; Pei, J.; Du, Y.; Gebremedhin, A.; Kirkevold, Ø. Towards Crowd-Sourced Air Quality and Physical Activity Monitoring by a Low-Cost Mobile Platform. Comput. Vis. 2016, 9677, 451-463. [CrossRef]

118. Chew, R.; Thornburg, J.; Jack, D.; Smith, C.; Yang, Q.; Chillrud, S. Identification of Bicycling Periods Using the MicroPEM Personal Exposure Monitor. Sensors 2019, 19, 4613. [CrossRef]

119. US EPA, Nitrogen Dioxide (NO2) Pollution, United States Environ. Prot. Agency. (2017) 1. Available online: https:/ /www.epa. gov/no2-pollution/basic-information-about-no2\#Effects (accessed on 9 June 2021).

120. US EPA, Carbon Monoxide (CO) Pollution in Outdoor Air, 19 January 2017 Web Snapshot. 2020. Available online: https: / / www.epa.gov/co-pollution (accessed on 9 June 2021).

121. Saoutieff, E.; Polichetti, T.; Jouanet, L.; Faucon, A.; Vidal, A.; Pereira, A.; Boisseau, S.; Ernst, T.; Miglietta, M.; Alfano, B.; et al. A Wearable Low-Power Sensing Platform for Environmental and Health Monitoring: The Convergence Project. Sensors 2021, 21, 1802. [CrossRef]

122. Haghi, M.; Geissler, A.; Fleischer, H.; Stoll, N.; Thurow, K. Ubiqsense: A Personal Wearable in Ambient Parameters Monitoring based on IoT Platform. In Proceedings of the 2019 International Conference on Sensing and Instrumentation in IoT Era (ISSI), Lisbon, Portugal, 29-30 August 2019.

123. Haghi, M.; Thurow, K.; Stoll, N. A multi-layer multi-sensor wearable device for physical and chemical environmental parameters monitoring $\left(\mathrm{CO} \& \mathrm{NO}_{2}\right)$. In Proceedings of the 2017 International Conference on Information and Digital Technologies (IDT), Zilina, Slovakia, 5-7 July 2017.

124. Serbanescu, M.; Placinta, V.M.; Hutanu, O.E.; Ravariu, C. Smart, low power, wearable multi-sensor data acquisition system for environmental monitoring. In Proceedings of the 2017 10th International Symposium on Advanced Topics in Electrical Engineering (ATEE), Bucharest, Romania, 23-25 March 2017.

125. Wu, F.; Rüdiger, C.; Redouté, J.-M.; Yuce, M.R. A Wearable Multi-sensor IoT Network System for Environmental Monitoring. In Advances in Body Area Networks; Springer: Cham, Switzerland, 2018; pp. 29-38.

126. Wu, F.; Rudiger, C.; Redoute, J.-M.; Yuce, M.R. WE-Safe: A wearable IoT sensor node for safety applications via LoRa. In Proceedings of the 2018 IEEE 4th World Forum on Internet of Things (WF-IoT); Institute of Electrical and Electronics Engineers (IEEE), Singapore, 5-8 February 2018.

127. Sempionatto, J.R.; Mishra, R.K.; Martín, A.; Tang, G.; Nakagawa, T.; Lu, X.; Campbell, A.S.; Lyu, K.M.; Wang, J. Wearable Ring-Based Sensing Platform for Detecting Chemical Threats. ACS Sensors 2017, 2, 1531-1538. [CrossRef]

128. Sound Pressure Level Extension. Available online: https://gldias.github.io/extensions/SoundPressureLevel/SoundPressureLevel_ Devel (accessed on 9 June 2021).

129. MIT App Inventor: Sensor Components. Available online: http://ai2.appinventor.mit.edu/reference/components/sensors.html (accessed on 9 June 2021).

130. Tsiastoudis, D.; Polatoglou, H. Inclusive education on stem subjects with the arduino platform. In Proceedings of the 8th International Conference on Software Development and Technologies for Enhancing Accessibility and Fighting Info-exclusion, Thessaloniki, Greece, 20-22 June 2018.

131. Vidal-Silva, C.; Serrano-Malebran, J.; Pereira, F. Scratch and Arduino for Effectively Developing Programming and ComputingElectronic Competences in Primary School Children. In Proceedings of the 2019 38th International Conference of the Chilean Computer Science Society (SCCC), Concepcion, Chile, 4-9 November 2019.

132. Khalsa, S.B.; Jewett, M.E.; Cajochen, C.; Czeisler, C.A. A Phase Response Curve to Single Bright Light Pulses in Human Subjects. J. Physiol. 2003, 549, 945-952. [CrossRef] 